\title{
WestVirginiaUniversity
}

THE RESEARCH REPOSITORY @ WVU

Graduate Theses, Dissertations, and Problem Reports

2006

\section{An evaluation of the Bailey Method to predict voids in the mineral aggregate}

Craig Mason

West Virginia University

Follow this and additional works at: https://researchrepository.wvu.edu/etd

\section{Recommended Citation}

Mason, Craig, "An evaluation of the Bailey Method to predict voids in the mineral aggregate" (2006). Graduate Theses, Dissertations, and Problem Reports. 3263.

https://researchrepository.wvu.edu/etd/3263

This Thesis is protected by copyright and/or related rights. It has been brought to you by the The Research Repository @ WVU with permission from the rights-holder(s). You are free to use this Thesis in any way that is permitted by the copyright and related rights legislation that applies to your use. For other uses you must obtain permission from the rights-holder(s) directly, unless additional rights are indicated by a Creative Commons license in the record and/ or on the work itself. This Thesis has been accepted for inclusion in WVU Graduate Theses, Dissertations, and Problem Reports collection by an authorized administrator of The Research Repository @ WVU. For more information, please contact researchrepository@mail.wvu.edu. 
An Evaluation of the Bailey Method to Predict

Voids in the Mineral Aggregate

\section{Craig Mason}

Thesis submitted to the College of Engineering and Mineral Resources at West Virginia University in partial fulfillment of the requirements for the degree of

Master of Science

In

Civil Engineering

Dr. John P. Zaniewski, Chair

Dr. Ronald W. Eck

Mr. Thomas Medvick

Department of Civil and Environmental Engineering

Morgantown, West Virginia

2006

Keywords: SuperPave, Marshall, asphalt mix design, Bailey Method, aggregate gradations 


\section{ABSTRACT \\ An Evaluation of the Bailey Method to Predict Voids in the Mineral Aggregate}

\section{Craig Mason}

The Bailey Method was developed by Robert Bailey of the Illinois State DOT. It was intended to be a tool to predict changes in voids in the mineral aggregate (VMA) resulting from gradation alterations in compacted asphalt concrete samples. This research evaluates the changes in VMA due to gradation alterations of four contractors' mix designs. By providing a tool to predict VMA, a desired gradation for asphalt mixtures can be developed to create a strong aggregate skeleton for rut resistance, durability, and adequate VMA.

The objective of this research was to evaluate the Bailey Method to predict voids in the mineral aggregate. The research included analysis on mix designs for SuperPave $9.5 \mathrm{~mm}$ and $19 \mathrm{~mm}$ mixtures and a Marshall Wearing I. The SuperPave mixtures used crushed limestone aggregate while the Marshall used crushed gravel. The correlation between the Bailey Method predictions and laboratory results were evaluated. 


\section{ACKNOWLEDGEMENTS}

I would like to express my gratitude to Dr. John Zaniewski for his continual guidance throughout my research. Without his guidance, this research would not have been possible.

I would also like to thank Dr. Ronald Eck and Mr. Thomas Medvick, members of my thesis committee, for their time and guidance.

Special thanks to Rich Nuzum, Greer Industries, and Dallas Boggess, West Virginia Paving Company, for their assistance and providing aggregate material and mix designs for this research.

Finally, I would like to thank my entire family, especially my brother Eric for their support and motivation. 


\section{TABLE OF CONTENTS}

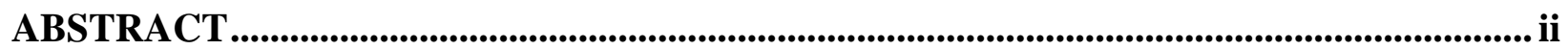

ACKNOWLEDGEMENTS .......................................................................................................ii

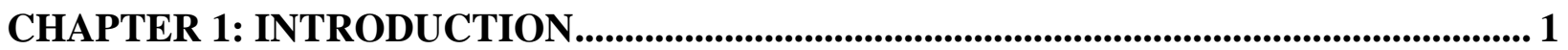

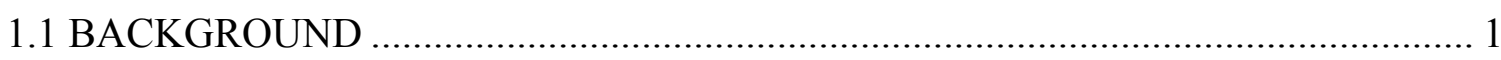

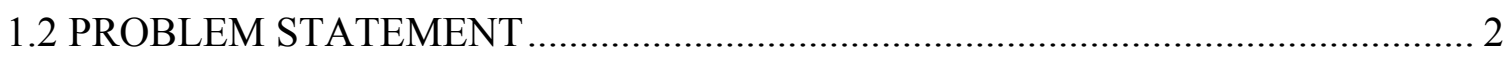

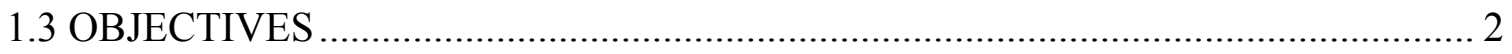

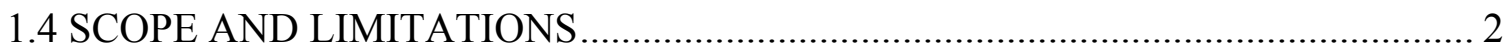

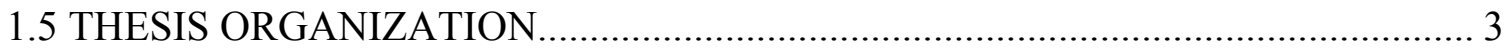

CHAPTER 2: LITERATURE REVIEW....................................................................................... 4

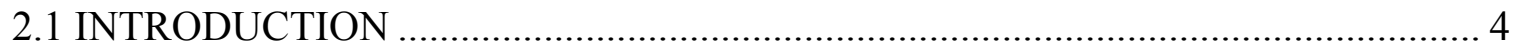

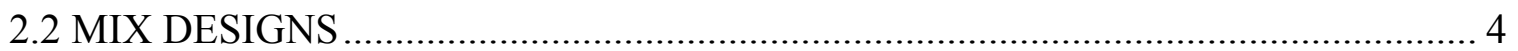

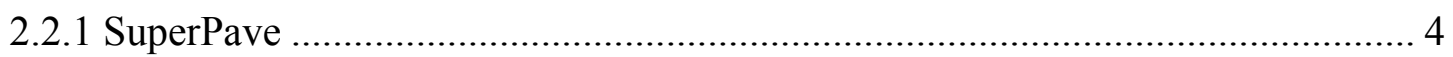

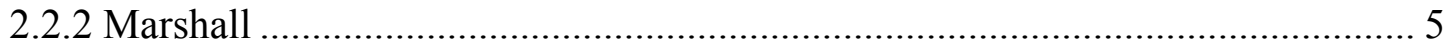

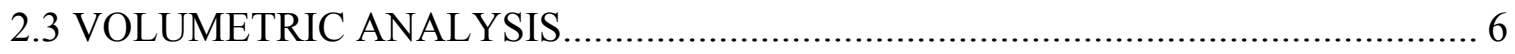

2.4 ASPHALT FILM THICKNESS …………………….......................................... 8

2.5 BAILEY METHOD

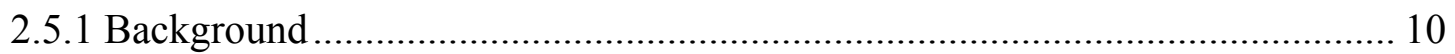

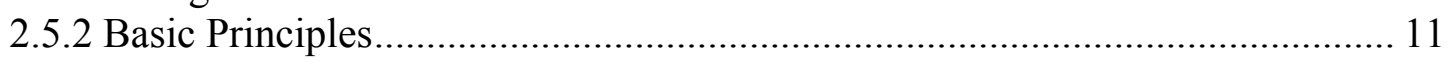

2.5.3 Combining Aggregates by Volume ............................................................. 13

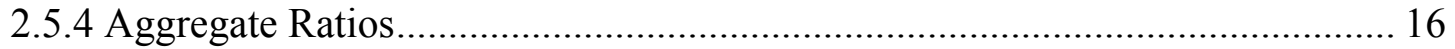

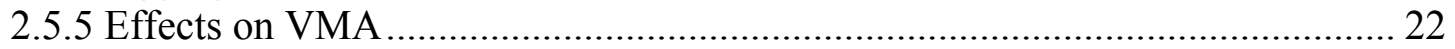

CHAPTER 3: RESEARCH METHODOLOGY _..................................................................... 24

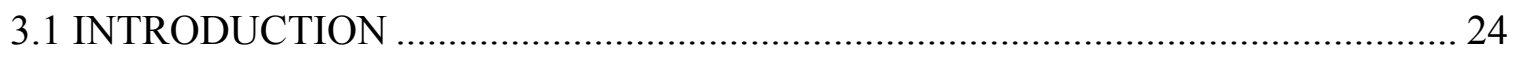

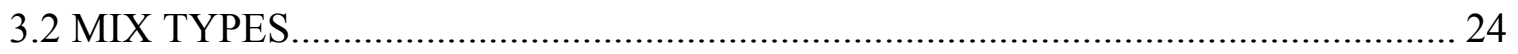

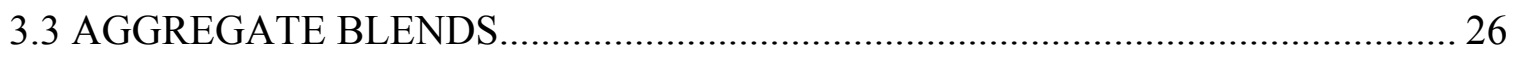

3.4 UNIT WEIGHT OF AGGREGATE............................................................... 32

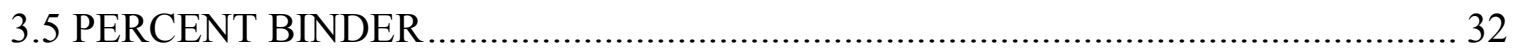




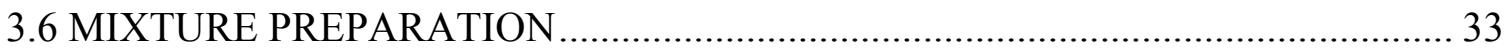

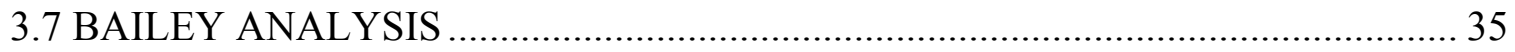

3.7.1 Contractor's Mix Design Analysis.................................................................. 35

3.7.2 Coarse and Fine Blends Design ...................................................................... 36

3.7.3 Greer Asphalt 9.5mm Coarse Mixture Example................................................ 38

3.7.4 West Virginia Paving Wearing I Fine Mixture Example.................................... 39

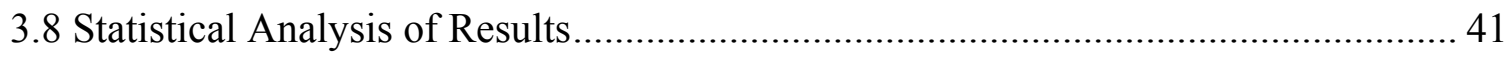

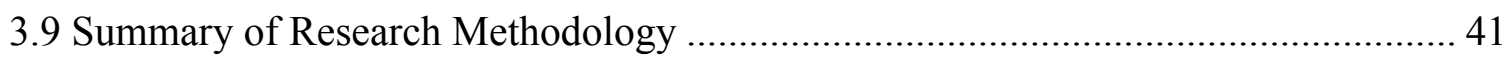

CHAPTER 4: COMPUTER ANALYSIS OF BAILEY METHOD .......................................... 42

CHAPTER 5: RESULTS AND ANALYSIS............................................................................... 48

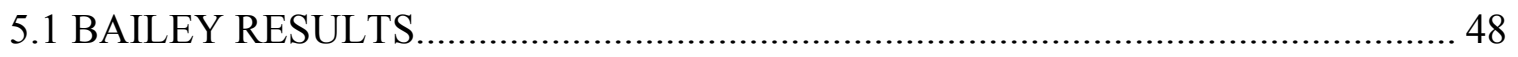

5.2 ANALYSIS FOR 9.5MM AGGREGATE MIXTURES ………………………........ 52

5.3 ANALYSIS FOR 19MM AGGREGATE MIXTURES ………………………….... 54

CHAPTER 6: CONCLUSIONS AND RECOMMENDATIONS..............................................56

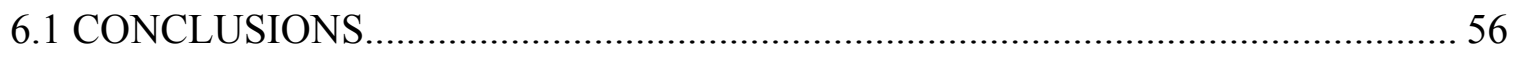

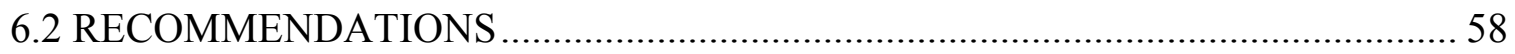

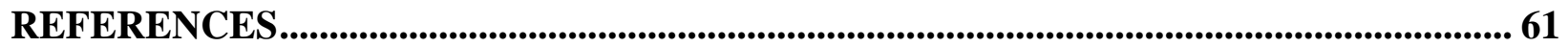

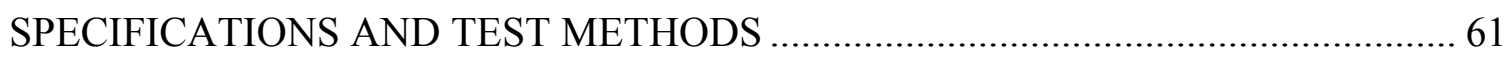

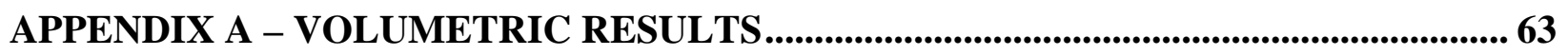

APPENDIX B - ANOVA.......................................................................................................................... 67 


\section{LIST OF FIGURES}

Figure 2.1 Separation between Bailey Coarse and Fine Aggregate for 19mm NMPS ............... 13

Figure 2.2 Loose Versus Rodded Unit Weight Compacted Aggregate Samples ...................... 14

Figure 2.3 Selection of Chosen Unit Weight for Coarse Aggregate........................................ 16

Figure 2.4 Estimation of Void Size between Aggregates for Bailey Control Sieves .................. 17

Figure 2.5 Chosen Unit Weight vs. Change in VMA ........................................................... 23

Figure 3.1 Gradation Chart for Greer 9.5mm Aggregate...................................................... 28

Figure 3.2 Gradation Chart for Greer 19mm Aggregate.................................................... 29

Figure 3.3 Gradation Chart for West Virginia Paving 9.5mm Aggregate ................................ 30

Figure 3.4 Gradation Chart for West Virginia Paving Wearing I Aggregate ............................. 31

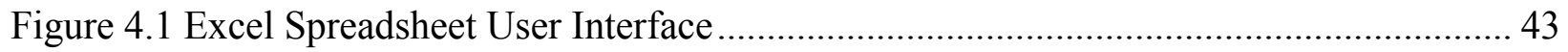

Figure 5.1 VMA Correlations - WVU Lab and Bailey Prediction for All Samples ................... 51

Figure 5.2 VMA Correlations - WVU Lab and Bailey Prediction for SuperPave Mixtures ........ 51

Figure 5.3 VMA vs. Chosen Unit Weight for 9.5mm Aggregate Mixtures at Low Asphalt

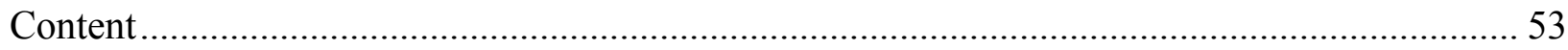

Figure 5.4 VMA vs. Chosen Unit Weight for 9.5mm Aggregate Mixtures at Target Asphalt

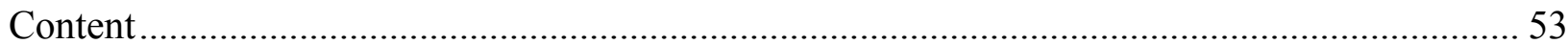

Figure 5.5 VMA vs. Chosen Unit Weight for 9.5mm Aggregate Mixtures at High Asphalt

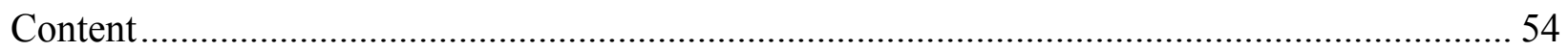

Figure 5.6 VMA vs. Chosen Unit Weight for 19mm Aggregate Mixtures ............................... 55

Figure 6.1 Coarse aggregates used in Marshall and SuperPave $9.5 \mathrm{~mm}$ mixes........................ 57 


\section{LIST OF TABLES}

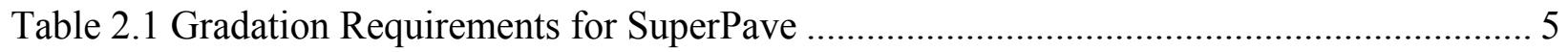

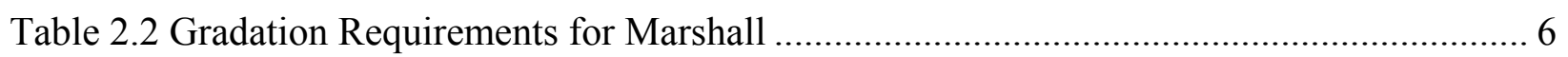

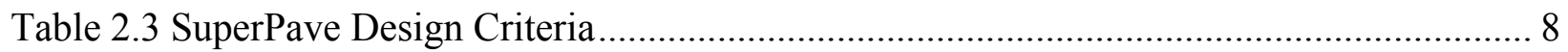

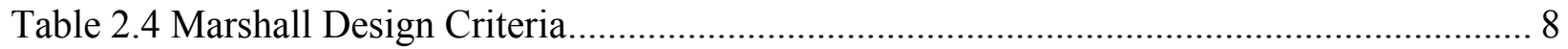

Table 2.5 Surface Area Factors for Computing Asphalt Film Thickness ................................... 10

Table 2.6 Bailey Coarse and SMA Graded Mixture Control Sieves ............................................. 18

Table 2.7 Bailey Fine Graded Mixture Control Sieves........................................................... 18

Table 2.8 Aggregate Ratios for Coarse and SMA Graded Mixtures ........................................... 20

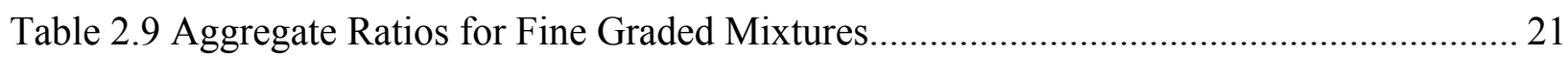

Table 2.10 Recommended Ranges of Aggregate Ratios for Coarse and Fine Mixtures .............. 21

Table 2.11 Recommended Ranges of Aggregate Ratios for SMA Mixtures................................. 22

Table 2.12 Effects of Increasing Bailey Parameters on VMA.................................................... 22

Table 2.13 Change in Value of Bailey Parameter to Produce 1\% Change in VMA .................... 23

Table 3.1 Sample Combinations ............................................................................................. 25

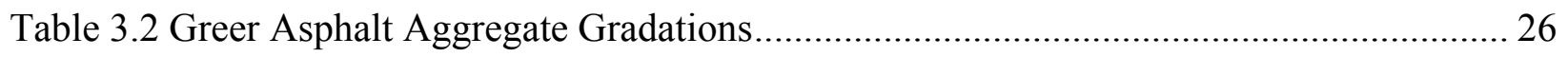

Table 3.3 West Virginia Paving Aggregate Gradations............................................................. 27

Table 3.4 Percent Chosen Unit Weight of Each Mixture …………………………………........ 27

Table 3.5 Asphalt Contents for Greer Mixes .......................................................................... 33

Table 3.6 Asphalt Contents for West Virginia Paving Mixes ..................................................... 33

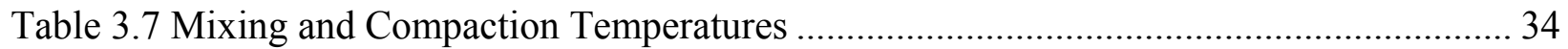

Table 3.8 Recommended Bailey Aggregate Ratios and Contractors' Ratios ................................ 36

Table 3.9 Recommended Bailey Aggregate Ratios and Coarse and Fine Blends ......................... 37

Table 3.10 Changes in VMA According to Bailey Parameters and Overall Net Change ............. 38

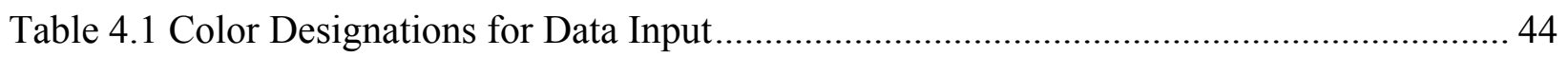

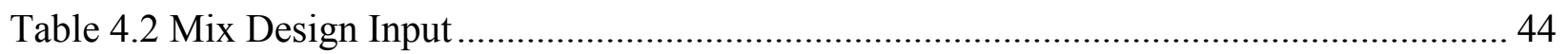

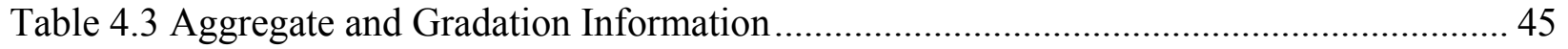

Table 4.4 Chosen Unit Weight and Desired Blend Volumes ………………………................... 46

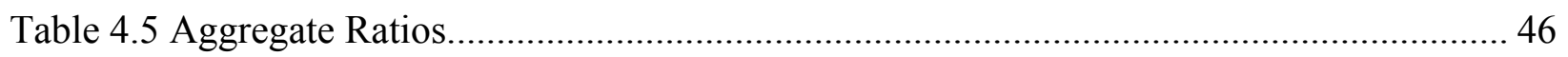

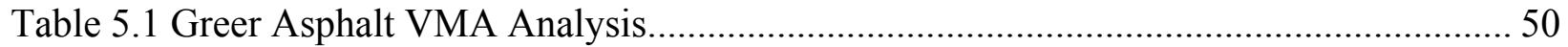

Table 5.2 West Virginia Paving VMA Analysis ................................................................... 50 


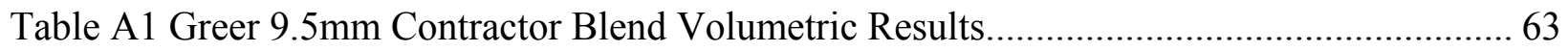

Table A2 Greer 9.5mm Coarse Blend Volumetric Results.................................................. 63

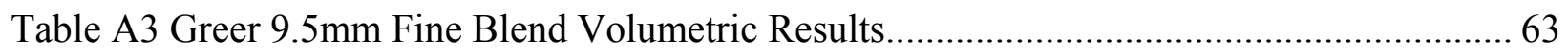

Table A4 Greer 19mm Contractor Blend Volumetric Results.............................................. 64

Table A5 Greer 19mm Coarse Blend Volumetric Results..................................................... 64

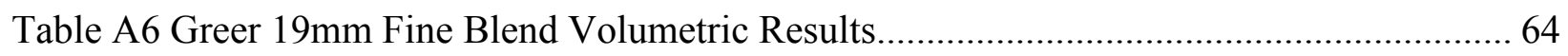

Table A7 West Virginia Paving 9.5mm Contractor Blend Volumetric Results ....................... 65

Table A8 West Virginia Paving 9.5mm Coarse Blend Volumetric Results ............................ 65

Table A9 West Virginia Paving 9.5mm Fine Blend Volumetric Results ................................ 65

Table A10 West Virginia Paving Wearing I Contractor Blend Volumetric Results .................. 66

Table A11 West Virginia Paving Wearing I Coarse Blend Volumetric Results ........................ 66

Table A12 West Virginia Paving Wearing I Fine Blend Volumetric Results ........................... 66

Table B1 Regression Analysis of VMA for Bailey Prediction versus WVU Lab Results for All

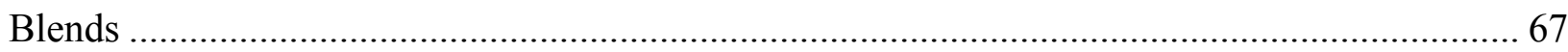

Table B2 Regression Analysis of VMA for Bailey Prediction versus WVU Lab Results for

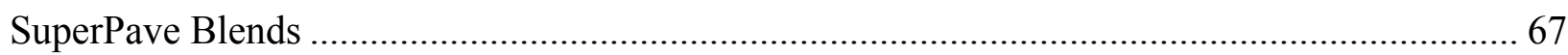




\section{CHAPTER 1: INTRODUCTION}

\subsection{BACKGROUND}

A hot mix asphalt mixture is a composite of aggregate material, asphalt binder, and air. The performance of a bituminous pavement is directly related to the proportions of each of these materials. Determining the proper proportions of each material allows for a better performing pavement product. The various mix design methods, such as Marshall and SuperPave, were developed to establish the proper proportions of binder, aggregates and air voids. However, other than the control points used to restrict the gradation of aggregate blends, the mix design methods do not allow the designer to analytically evaluate the effects of changes in gradations on mix properties.

The Bailey Method was developed by Robert Bailey, a retired materials engineer for the Illinois Department of Transportation. The method develops a strategy to create a strong aggregate skeleton for rut resistance, durability, and adequate voids in the mineral aggregate. A strong aggregate structure is important because the aggregate supports most of the compressive forces. The Bailey Method is based on how the coarse and fine aggregates pack together to form a strong aggregate skeleton.

Originally the main tool for engineers to increase voids in the mineral aggregate was to use the 0.45 -power grading chart for aggregates. The voids in the mineral aggregate could be increased by adjusting the gradation farther away from the maximum density line. There were no strict guidelines on how gradation changes would alter mixture properties. The Bailey Method was developed to provide a guideline (Vavrik, et. al., 2002). 


\subsection{PROBLEM STATEMENT}

The Bailey Method for predicting voids in the mineral aggregate is beneficial in determining a proper gradation, given a specific stockpile blend of aggregate, to meet volumetric requirements. This research work compares the effects of gradation changes on the voids in the mineral aggregate by predicting the outcome with the Bailey Method. SuperPave and Marshall mix designs are evaluated by the method. Although the calculations used for the Bailey analysis are not difficult, they are confusing. An Excel spreadsheet was developed to assist the designer with the analysis (Microsoft, 2003).

\subsection{OBJECTIVES}

The objective of this research is to compare the predicted results of VMA changes, from gradations variations using the Bailey Method, verses the results conducted in the laboratory. The main interest is to see how adequately the Bailey Method can predict VMA changes using both Marshall and SuperPave design methodologies. By knowing the predicted values of VMA, the characteristics of how the aggregates pack together to form the asphalt structure can be better understood.

\subsection{SCOPE AND LIMITATIONS}

This research used 9.5mm and 19mm SuperPave and Wearing I Marshall mixes for the analysis. The original mix designs were provided from Greer Asphalt and West Virginia Paving. Asphalt binder was used according to the mix designs provided by the contractors and consisted of PG 64-22 and PG 70-22 from Marathon Ashland. The original designs were analyzed and developed into both a coarser and a finer mix. The three different variations were then analyzed by the Bailey Method to predict VMA changes from the change in gradation to coarser and finer. The main limitation was the lack of resource information and previous research using this 
method. The Transportation Research Board was the main information source that was recovered through extensive searches (Vavrik, et. al., 2002). The Excel spreadsheet is capable of analyzing Stone Matrix Asphalt (SMA) mixtures by the Bailey Method, although the West Virginia Department of Transportation does not design SMA mixtures. Therefore, this research did not test SMA mixtures in the laboratory.

\subsection{THESIS ORGANIZATION}

This thesis is organized into six chapters and an appendix. Following the Introduction, Chapter 2 is a literature review that explains SuperPave and Marshall mix designs, the basics of asphalt film thickness, volumetric equations, and the procedure of the Bailey Method. Chapter 3 explains the research methodology and procedures for testing and analyzing the hot mix asphalt samples according to the Bailey procedure. Chapter 4 shows the computer analysis program developed to calculate the Bailey Method results. Chapter 5 shows the results from the conducted experiments and the relativity to the Bailey Method. Chapter 6 concludes the main portion of the report with conclusions and recommendations for future analyses. The final appendix details the test data and calculations involved in preparing test samples and conducting the analysis through the Bailey Method procedure. 


\section{CHAPTER 2: LITERATURE REVIEW}

\subsection{INTRODUCTION}

The following literature review discusses the Bailey Method for gradation selection in hot mix asphalt mixture design. The review first gives background information on SuperPave and Marshall mix design methods. The volumetric calculations and concept of film thickness are then discussed in the review. The remaining proportion of the review discusses the background and utilization of the Bailey Method.

\subsection{DESIGNS}

\subsubsection{SuperPave}

The SuperPave (an acronym for Superior Performing Asphalt Pavement System) method was developed through the Strategic Highway Research Program (SHRP) as an initiative to develop an improved mix design procedure. A new method of mix design was desired to design for various traffic volumes, axle loads, and environments. The SuperPave method was developed to provide tests and models to predict potential rutting, thermal cracking, and fatigue cracking (Roberts, et. al., 1996).

The SuperPave method evaluates the volumetric properties of compacted hot mix asphalt concrete samples to analyze the quality of the mix and to determine the design asphalt content. The samples are compacted by a SuperPave gyratory compactor. This compaction device was developed to simulate the compaction of asphalt by orienting the aggregate particles similar to what is observed in the field condition. The gyratory compactor induces a shearing action during compaction by providing vertical pressure, angle and speed of gyration, and number of gyrations. The number of gyrations is specified according to the traffic level and average design high air temperature. High air temperatures and high levels of traffic cause the asphalt to densify more 
and require higher laboratory compaction densities. The SuperPave procedure specifies a vertical pressure of $600 \mathrm{kPa}(87 \mathrm{psi})$, an angle of gyration of $1.25^{\circ}$, and a gyration speed of 30 revolutions per minute.

The SuperPave method requires gradation controls for determining the aggregate blend of the mixture. The control points specify ranges for allowable percent of aggregate to pass a designated sieve size. SuperPave defines a primary control sieve which is the separation point between a coarse and fine mixture according to SuperPave criteria. The control points and primary control sieve requirements are shown in Table 2.1 (WVDOT MP 401.02.29, 2000).

\section{Table 2.1 Gradation Requirements for SuperPave}

\begin{tabular}{|c|c|c|}
\hline & \multicolumn{2}{|c|}{ Nominal Maximum Aggregate Size } \\
\hline Sieve Size & $\mathbf{9 . 5} \mathbf{~ m m}$ & $\mathbf{1 9} \mathbf{~ m m}$ \\
\hline $\mathbf{2 5}$ & & 100 \\
\hline $\mathbf{1 9}$ & & $90-100$ \\
\hline $\mathbf{1 2 . 5}$ & 100 & $90 \mathrm{max}$ \\
\hline $\mathbf{9 . 5}$ & $90-100$ & \\
\hline $\mathbf{4 . 7 5}$ & $90 \mathrm{max}$ & $47^{*}$ \\
\hline \multirow{2}{2.36}{} & $32-67$ & \multirow{2}{*}{$23-49$} \\
\cline { 2 - 3 } & $47^{*}$ & $2.0-8.0$ \\
\hline $\mathbf{0 . 0 7 5}$ & $2.0-10.0$ & \\
\hline
\end{tabular}

* SuperPave Primary Control Sieve

\subsubsection{Marshall}

The Marshall method was originally developed by Bruce Marshall of the Mississippi State Highway Department in 1939. The U.S. Army Corps of Engineers experimented with the Marshall design to develop its current form and standard compaction apparatus (Roberts, et. al., 1996).

The Marshall mix design method uses the mixture's stability, flow, and volumetric parameters to analyze the quality of the mix and determine an optimal asphalt content. These parameters are determined from compacted samples obtained from using a Marshall compactor. 
This apparatus compacts the asphalt concrete samples by dropping a hammer from a consistent height for a specified number of blows per side. The Marshall specifications for number of blows per side are 35 for light traffic, 50 for medium traffic, and 75 for heavy traffic. West Virginia does not use the light traffic compaction level.

The Marshall method requires gradation controls for determining the aggregate blend of the mixture. The control points specify ranges for allowable percent of aggregate to pass a designated sieve size. The control point requirements for Marshall mix designs are shown in Table 2.2 (WVDOT MP 401.02.22, 2000).

\section{Table 2.2 Gradation Requirements for Marshall}

\begin{tabular}{|c|c|}
\hline $\begin{array}{c}\text { Sieve } \\
\text { Size }\end{array}$ & Marshall Wearing I \\
\hline $\mathbf{1 2 . 5}$ & 100 \\
\hline $\mathbf{9 . 5}$ & $85-100$ \\
\hline $\mathbf{4 . 7 5}$ & $80 \mathrm{max}$ \\
\hline $\mathbf{2 . 3 6}$ & $30-55$ \\
\hline $\mathbf{0 . 0 7 5}$ & $2.0-9.0$ \\
\hline
\end{tabular}

\subsection{VOLUMETRIC ANALYSIS}

The volumetric analysis is calculated from the values for bulk specific gravity $\left(\mathrm{G}_{\mathrm{sb}}\right)$ and theoretical specific gravity $\left(\mathrm{G}_{\mathrm{mm}}\right)$. The values for these specific gravities are determined using AASHTO T166 and AASHTO T209, respectively. The volumetric parameters are the voids in the mineral aggregate (VMA), voids in total mix (VTM), voids filled with asphalt (VFA), and the dust-to-binder ratio. For Marshall mix designs, an addition parameter for stability and flow (AASTO T245) must be evaluated. The equations for these parameters are listed below (Roberts, et. al., 1996). 
$V M A=100\left(1-\frac{G_{m b}\left(1-P_{b}\right)}{G_{s b}}\right)$

$V T M=100\left(1-\frac{G_{m b}}{G_{m m}}\right)$

$V F A=100\left(\frac{V M A-V T M}{V M A}\right)$

SuperPave $\frac{\text { Dust }}{\text { Binder }}=\frac{\left(\frac{P_{200}}{100}\right)}{P_{b e}}$

Marshall $\frac{\text { Dust }}{\text { Binder }}=\frac{\left(\frac{P_{200}}{100}\right)}{P_{b}}$

where

$$
\begin{aligned}
& \text { VMA = volume of voids in mineral aggregate } \\
& \text { VTM = air voids in the total compacted mix } \\
& \text { VFA = voids filled with asphalt } \\
& G_{\mathrm{mb}}=\text { bulk specific gravity of compacted mix } \\
& \mathrm{G}_{\mathrm{sb}}=\text { bulk specific gravity of aggregate } \\
& \mathrm{G}_{\mathrm{mm}}=\text { theoretical maximum specific gravity } \\
& \mathrm{P}_{200}=\text { percent aggregate passing the } \# 200 \text { sieve } \\
& \mathrm{P}_{\mathrm{be}}=\text { effective percent binder } \\
& \mathrm{P}_{\mathrm{b}}=\text { percent binder }
\end{aligned}
$$

SuperPave uses the effective binder content for the dust to binder ratio, while Marshall uses the total percent binder for this ratio. The design volumetric criteria for SuperPave and Marshall mix designs according AASHTO and WVDOT standard specifications are shown in Tables 2.3 and 2.4. 
Table 2.3 SuperPave Design Criteria

\begin{tabular}{|c|c|c|}
\cline { 2 - 3 } \multicolumn{1}{c|}{} & \multicolumn{2}{c|}{ Nominal Maximum Aggregate Size } \\
\hline Design Criteria & $\mathbf{9 . 5} \mathbf{~ m m}$ & $\mathbf{1 9} \mathbf{~ m m}$ \\
\hline Air Voids (\%) & 4.0 & 4.0 \\
\hline VMA (\%) & $15 \mathrm{~min}$ & $13 \mathrm{~min}$ \\
\hline VFA (\%) & $73-76$ & $65-75$ \\
\hline Dust-to-Binder & $0.8-1.6$ & $0.6-1.2$ \\
\hline
\end{tabular}

Table 2.4 Marshall Design Criteria

\begin{tabular}{|c|c|}
\hline Design Criteria & Heavy Traffic \\
\hline Compaction, \# of blows per side & 75 \\
\hline Stability (N) & $8000 \mathrm{~min}$ \\
\hline Flow (0.25mm) & $8-14$ \\
\hline Air Voids (\%) & $3-5$ \\
\hline VMA (\%) & $15 \mathrm{~min}$ \\
\hline VFA (\%) & $65-76$ \\
\hline Dust-to-Binder & $0.8-1.6$ \\
\hline
\end{tabular}

\subsection{ASPHALT FILM THICKNESS}

Asphalt film thickness is the thickness of asphalt cement that coats the surface of the aggregate particles in the mixture. Asphalt film thickness is not directly considered as part of mixture design. However, the voids in the mineral aggregate, which can be determined from laboratory tests is related to asphalt film thickness; so film thickness is controlled in an indirect manner. The film thickness is calculated based on the surface area of the aggregate and the volume of asphalt in the mixture (Roberts, et. al., 1996). The surface area of the aggregate is directly affected by the gradation of the mixture. Since fine aggregates have a higher surface area per unit weight than coarse aggregates, the finer the aggregate blend the higher the surface area. In order to maintain a consistent asphalt film thickness, the effective percent binder of a mixture must be increased as a function of the fineness of the aggregate blend. Equation 2.5 shows the calculations to determine asphalt film thickness (Roberts, et. al., 1996). 
$T_{F}=\frac{V_{b e}}{S A \times M_{s}} \times \rho_{w}$

where

$$
\begin{aligned}
& \mathrm{T}_{\mathrm{F}}=\text { average film thickness } \\
& \mathrm{V}_{\mathrm{be}}=\text { effective volume of asphalt binder } \\
& \mathrm{SA}=\text { surface area of aggregate } \\
& \mathrm{M}_{\mathrm{S}}=\text { mass of aggregate } \\
& \rho_{\mathrm{w}}=\text { density of water }
\end{aligned}
$$

The surface area factors used for the calculation of the asphalt film thickness were originally developed by Hveem and Edwards (Kandhal, et. al., 1998). When SuperPave was developed, the VMA criteria from the Marshall method were retained as required mix design parameters. Kendhal, et. al. (1998) examined the use of these VMA criteria for SuperPave and made suggestions for altering the criteria. Zaniewski and Reyes (2003) evaluated Kandhal's work with respect to West Virginia aggregates. An alternative method for determining the surface area required in Equation 2.5 was developed. The surface area of the material larger than the No. 200 sieve was computed by assuming the aggregate retained on a sieve were spheres with a diameter equal to the average of the sieve the material was retained on and the next larger sieve. The surface area of the material passing the No. 200 sieve was measured using the Blaine air permeability apparatus, ASTM C-204. This method produced surface area factors given in Table 2.5. The surface area for an aggregate blend was computed as the sum of the percent of material retained on each sieve times the surface area factor. 
Table 2.5 Surface Area Factors for Computing Asphalt Film Thickness

\begin{tabular}{|c|c|c|}
\hline \multicolumn{2}{|c|}{ Sieve } & $\begin{array}{c}\text { Surface Aera } \\
\text { Factor }\end{array}$ \\
\hline $\mathbf{1}$ & $\mathbf{2 5}$ & 0.07 \\
\hline $\mathbf{3 / 4}$ & $\mathbf{1 9}$ & 0.10 \\
\hline $\mathbf{1 / 2}$ & $\mathbf{1 2 . 5}$ & 0.14 \\
\hline $\mathbf{3 / 8}$ & $\mathbf{9 . 5}$ & 0.21 \\
\hline$\# \mathbf{4}$ & $\mathbf{4 . 7 5}$ & 0.32 \\
\hline$\# \mathbf{8}$ & $\mathbf{2 . 3 6}$ & 0.64 \\
\hline$\# \mathbf{1 6}$ & $\mathbf{1 . 1 8}$ & 1.28 \\
\hline$\# \mathbf{3 0}$ & $\mathbf{0 . 6}$ & 2.54 \\
\hline$\# \mathbf{5 0}$ & $\mathbf{0 . 3}$ & 5.03 \\
\hline$\# \mathbf{1 0 0}$ & $\mathbf{0 . 1 5}$ & 10.06 \\
\hline \#200 & $\mathbf{0 . 0 7 5}$ & 20.13 \\
\hline \multicolumn{2}{|c|}{ Pan Sand } & 118.5 \\
\hline \multicolumn{2}{|c|}{ Pan Limestone } & 434.8 \\
\hline
\end{tabular}

\subsection{BAILEY METHOD}

\subsubsection{Background}

The Bailey Method is an approach to selecting aggregate gradations for hot mix asphalt mixture design that was developed by Robert Bailey of the Illinois Department of Transportation. The method is used to create a strong aggregate skeleton by developing the proper voids in the mineral aggregate to achieve good durability and rut resistance. The strong skeleton is created by enhancing aggregate interlock and aggregate structure. The method develops aggregate interlock as the primary support of the structure and a balanced gradation to complete the mixture. Desirable qualities in asphalt are achieved by understanding the packing characteristics of the aggregate through the Bailey Method. The method is directly based on the voids in the mineral aggregate (VMA), air voids, and the properties of compaction (Vavrik, et. al., 2002). The reference material for the Bailey Method in this literature review was extensively researched and only a limited source of reference material was found. This research 
included extensive internet searches and documents published by the Transportation Research Board.

The Bailey Method is not a mix design method, but a tool to be used to create a better hot mix asphalt concrete for pavements. The method can be used for any mix design method such as SuperPave, Marshall, Hveem, or stone matrix asphalts.

\subsubsection{Basic Principles}

The Bailey Method was developed under two basic principles: aggregate packing and the definition of coarse and fine aggregates. The two principles are the basis for the relationship between aggregate gradation and mixture volumetric properties.

Aggregate packing is the orientation of the aggregate particles after compaction. The level of compaction between the aggregate particles will determine the voids of the mixture because the aggregate particles cannot be completely packed to fill the entire volume completely. The level of packing for an asphalt mixture depends on the following:

- Type and amount of compaction energy. There are several types of compaction methods such as static pressure, impact, or shearing. Higher densities can be developed by increasing the compaction energy.

- Shape and size of the particle. Round particles often arrange into denser configurations than flat and elongated particles which tend to resist packing.

- Surface orientation and texture. Smoother aggregate particles tend to slide against each other more easily than particles with rough surfaces. This allows the particles to re-orient themselves more easily into denser configurations.

- Gradation of the mixture. Mixtures with varying particles sizes will pack more densely than mixtures with single-sized particles. 
- Strength of the particles. The strength of the particles will affect the amount of degradation that occurs during the compaction process.

The second principle is the designation of coarse aggregates from fine aggregates. Coarse aggregates are large particles that when placed in a unit volume create voids. Fine aggregates are small particles that can fill the voids that are created by the coarse aggregate in the mixture. Traditionally, the designation between fine and coarse aggregates was whether or not a particle passed the $4.75-\mathrm{mm}$ sieve. In the Bailey Method, the coarse and fine designation depends on the nominal maximum particle size (NMPS) of the mixture. The NMPS is defined according to the SuperPave definition. The sieve that controls the designation between coarse and fine aggregates according to Bailey is called the primary control sieve (PCS). This primary control sieve is not the same as the standard SuperPave primary control sieve ${ }^{1}$. The PCS is based on the NMPS which will vary for different types of mixtures. The PCS is determined by the following equation and should be rounded to the nearest sieve size:

$\mathrm{PCS}=$ NMPS $\mathrm{x} 0.22$

where

PCS $=$ Primary Control Sieve for entire blend

NMPS = Nominal Maximum Aggregate Size for overall blend (one sieve size larger than first to retain more than $10 \%$ )

The separation between the coarse and fine aggregates can been seen in the Figure 2.1

(Vavrik, et. al., 2002). The dashed lined in the figure represents the PCS to show the separation between the coarse and fine aggregates for a blend with a NMPS of $19 \mathrm{~mm}$.

\footnotetext{
${ }^{1}$ For the duration of the text, the term PCS (Primary Control Sieve) refers to the Bailey PCS and not the standard definition according to SuperPave.
} 


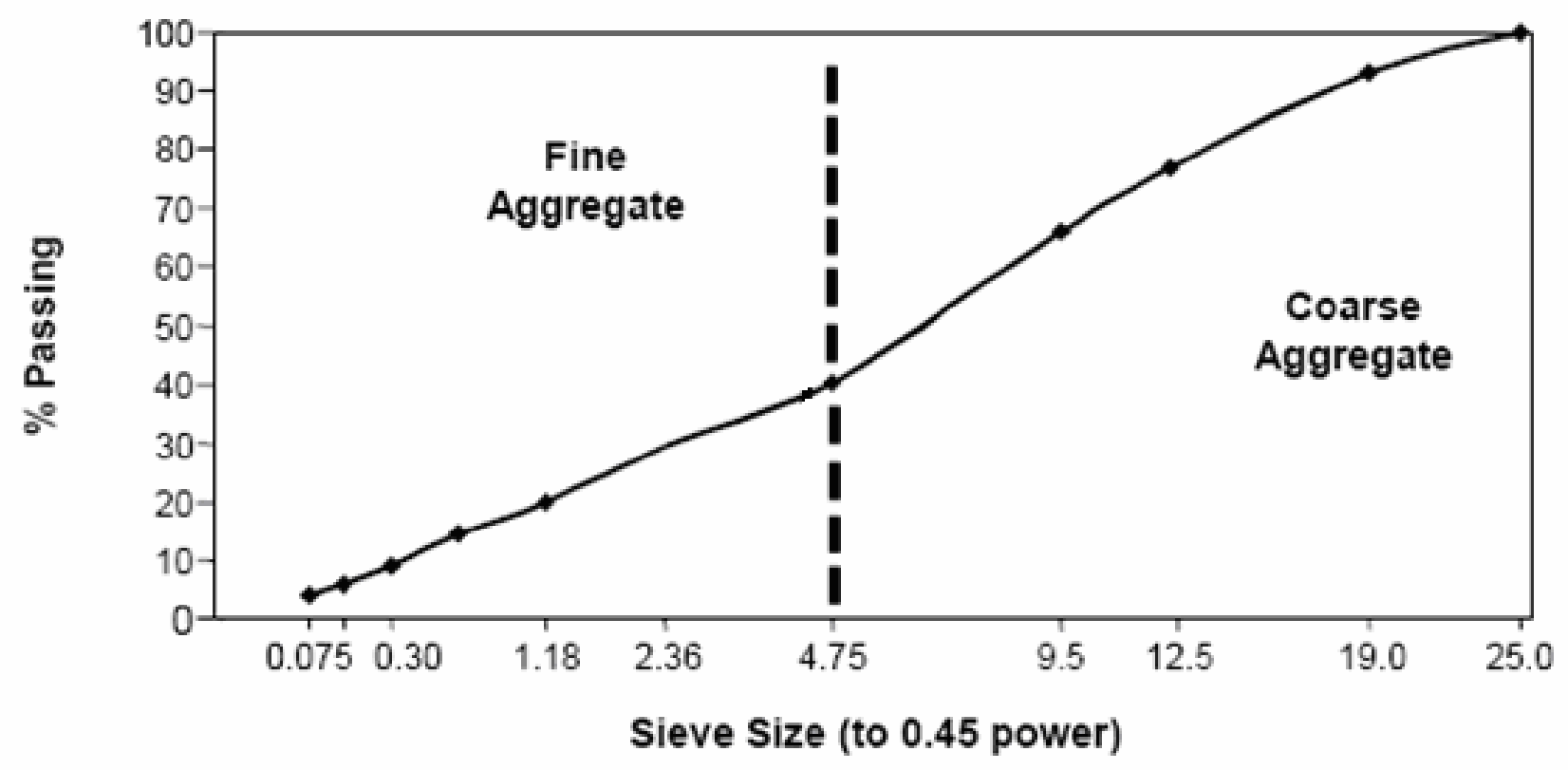

Figure 2.1 Separation between Bailey Coarse and Fine Aggregate for 19mm NMPS

\subsubsection{Combining Aggregates by Volume}

The coarse aggregate in the mixture create voids. The volume of voids must be calculated to determine the volume of fine aggregate needed to fill the voids. The mixtures are evaluated based on the volume to create a mixture with proper aggregate interlock, but for simplicity the aggregates are monitored on a weight basis. For coarse aggregates there are three governing weights ${ }^{2}$ that must be determined. The weights are the loose unit weight (LUW), rodded unit weight (RUW), and the chosen unit weight (CUW). The loose unit weight and the rodded unit weight can be seen in the Figure 2.2 (Vavrik, et. al., 2002).

\footnotetext{
${ }^{2}$ The term unit weight is used in the reference material for the Bailey Method, although the value is actually unit mass since the units are kilograms per meter cubed. The common term of unit weight is used throughout the text to comply with convention.
} 


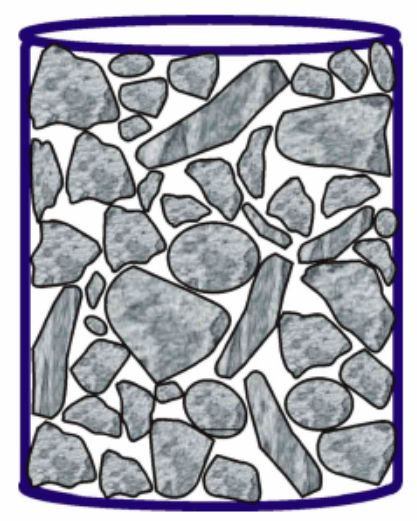

(a) Loose Condition

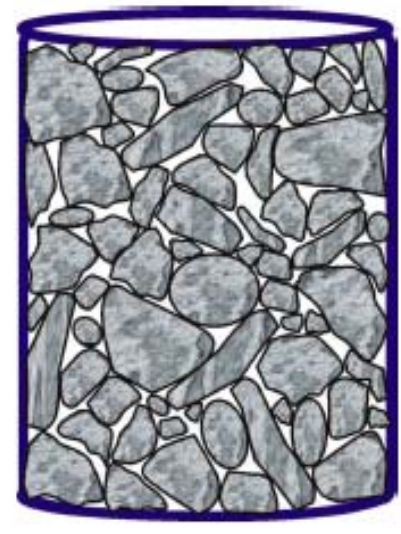

(b) Rodded Condition

\section{Figure 2.2 Loose Versus Rodded Unit Weight Compacted Aggregate Samples}

The loose unit weight is the amount of aggregate that fills a specified unit volume without any compaction energy applied to the aggregate. This value represents the beginning value of aggregate interlock before compaction. The loose unit weight is determined by the AASHTO T-19 Unit Weight and Voids in Aggregate procedure. The procedure requires the loose aggregate to be shoveled into a unit weight metal bucket and measured in the loose condition without compaction energy. The loose unit weight is determined by dividing the mass of the aggregate in the metal bucket by the volume of the metal bucket in $\mathrm{kg} / \mathrm{m}^{3}$.

The rodded unit weight is the amount of aggregate that fills a specified unit volume after compaction energy is applied to the aggregate. This value represents the value of aggregate interlock after compaction. The rodded unit weight is determined by the AASHTO T-19 Unit Weight and Voids in Aggregate procedure. The procedure requires filling the mold in three lifts and rodding each lift 25 times. The rodded unit weight is then determined by dividing the mass of the aggregate in the metal bucket by the volume of the metal bucket in $\mathrm{kg} / \mathrm{m}^{3}$. AASHTO T-19 specifies the container size should be increased as a function of the maximum aggregate size.

However, the recommended practice when evaluating aggregates for asphalt concrete is to use a 
container with a volume of $1 / 4 \mathrm{ft}^{3}\left(0.0071 \mathrm{~m}^{3}\right)$ for coarse aggregate and $1 / 30 \mathrm{ft}^{3}\left(0.00094 \mathrm{~m}^{3}\right)$ for fine aggregates (Pine, 2005).

The percent chosen unit weight is the value that the designer selects based on the desired interlock of coarse aggregate. The designer must decide if the mixture design is going to be a fine-graded mixture, dense-graded mixture, or a stone matrix mixture. After the mixture type is selected, the percent chosen unit weight can be selected.

The percent chosen unit weight is selected based on a percentage of the loose unit weight of coarse aggregate. The range for a dense graded coarse mixture is $95 \%$ to $105 \%$ of the loose unit weight of coarse aggregate for a mixture that will obtain some degree of coarse aggregate interlock. Values that exceed $105 \%$ of the loose unit weight of coarse aggregate are prone to increased aggregate degradation and difficulty of compaction in the field. Values greater than or equal to $110 \%$ are considered SMA mixtures and although difficult to construct in the field, SMA mixtures resist rutting and provide increased durability (Roberts, et. al., 1996).

The percent chosen unit weight for a fine graded mixture should be less than $90 \%$ of the loose unit weight of coarse aggregate. This will ensure that the load is carried predominantly by the fine aggregate structure. The percent chosen unit weight range between $90 \%$ and $95 \%$ should be avoided due to the high probability of varying in and out of coarse aggregate interlock. Figure 2.3 shows the selection of the chosen unit weight based on the percent of loose unit weight of coarse aggregate in the mixture (Vavrik, et. al., 2002).

The rodded unit weight of fine aggregates also needs to be determined. The unit weight is used to determine the volume of fine aggregate needed to fill the voids created by the coarse aggregate. Properly filling the voids will help maximum the strength of the fine aggregate structure. The rodded unit weight of fine aggregate is determined by the AASHTO T-19 Unit 


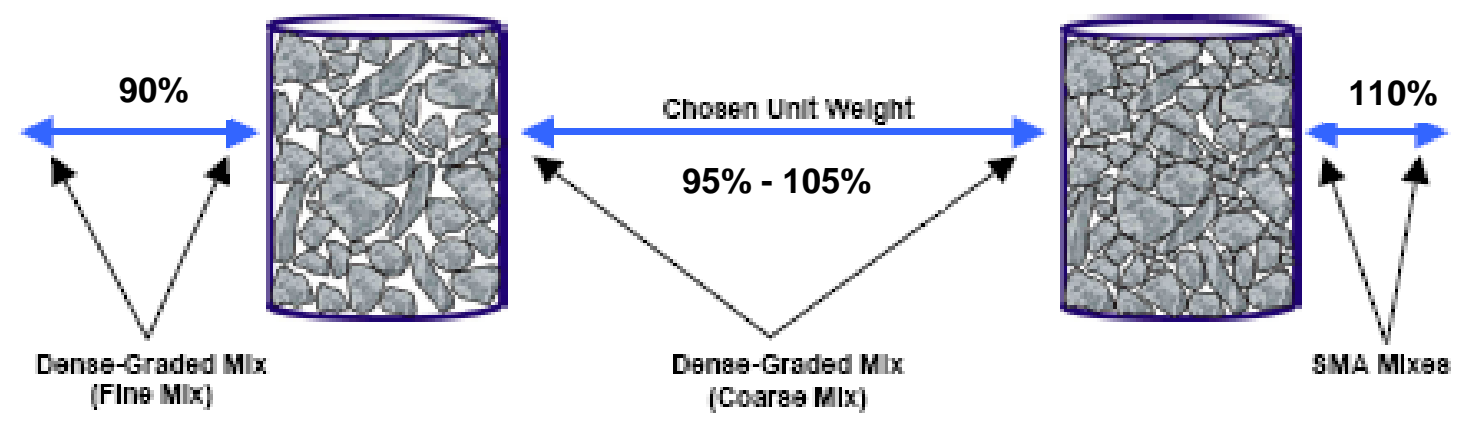

Figure 2.3 Selection of Chosen Unit Weight for Coarse Aggregate

Weight and Voids in Aggregate procedure. The procedure requires rodding the loose fine aggregate by applying compaction effort to the aggregate using a tamping rod. The rodded unit weight is calculated by dividing the weight of the aggregate by the volume of the bucket in $\mathrm{kg} / \mathrm{m}^{3}$ (Vavrik, et. al., 2002).

\subsubsection{Aggregate Ratios}

The combined blend is analyzed using three parameters: the coarse aggregate ratio (CA), the coarse portion of fine aggregate ratio $\left(\mathrm{FA}_{\mathrm{c}}\right)$, and the fine portion of the fine aggregate ratio $\left(\mathrm{FA}_{\mathrm{f}}\right)$. These parameters are calculated using the designated sieves:

- half sieve

- $\quad$ primary control sieve (PCS)

- $\quad$ secondary control sieve (SCS)

- $\quad$ tertiary control sieve (TCS)

The half sieve is the closest sieve to one half the nominal maximum particle size. The primary control sieve is the closest sieve to 22 percent of the nominal maximum particle size. The secondary control sieve is the closest sieve to 22 percent of the primary control sieve size and the 
tertiary control sieve is the closest sieve to 22 percent of the secondary control sieve. The 22 percent used to determine the Bailey control sieves is determined from the estimation of void size created by the four aggregate shape combinations as shown in Figure 2.4 (Aurilio, et. al., 2002).
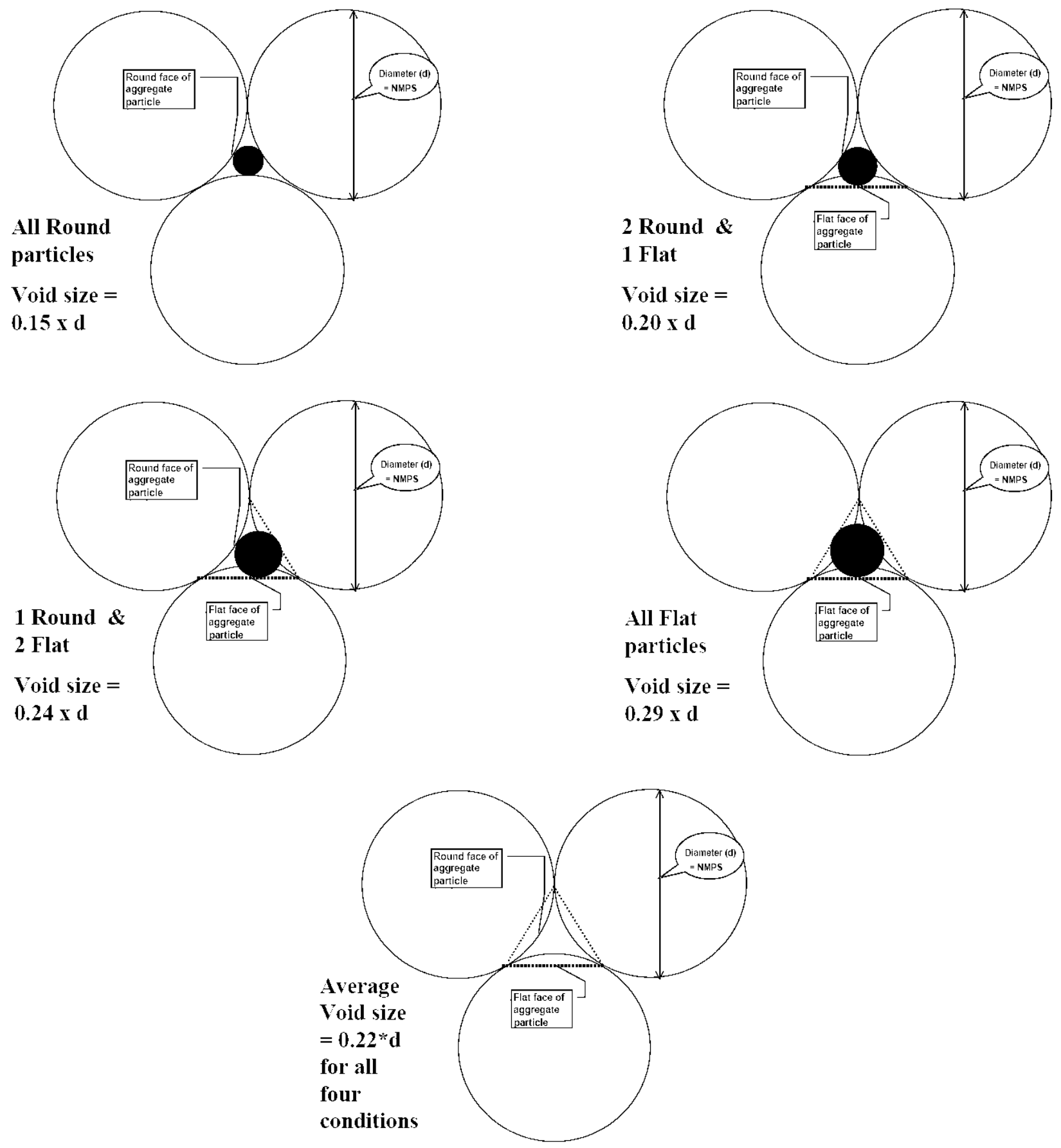

Figure 2.4 Estimation of Void Size between Aggregates for Bailey Control Sieves 
Table 2.6 shows the sieve size for each designated sieve based on the nominal maximum particle size for a Bailey coarse graded mixture.

Table 2.6 Bailey Coarse and SMA Graded Mixture Control Sieves

\begin{tabular}{|c|c|c|c|c|c|c|}
\cline { 2 - 7 } \multicolumn{1}{c|}{} & \multicolumn{7}{c|}{ NMPS, mm } \\
\hline DESIGNATED SIEVES & $\mathbf{3 7 . 5}$ & $\mathbf{2 5 . 0}$ & $\mathbf{1 9 . 0}$ & $\mathbf{1 2 . 5}$ & $\mathbf{9 . 5}$ & $\mathbf{4 . 7 5}$ \\
\hline Half Sieve & 19 & 12.5 & 9.5 & 4.75 & 4.75 & 2.36 \\
\hline PCS & 9.5 & 4.75 & 4.75 & 2.36 & 2.36 & 1.18 \\
\hline SCS & 2.36 & 1.18 & 1.18 & 0.6 & 0.6 & 0.3 \\
\hline TCS & 0.6 & 0.3 & 0.3 & 0.15 & 0.15 & 0.075 \\
\hline
\end{tabular}

For coarse and SMA mixes, the pavement loads are carried by the skeleton of coarse aggregates. For Bailey fine graded mixtures, there is too much space between the coarse particles to transfer the load, hence the load is carried by the fine particles and the voids between the "large" fine particles must be filled by the "finer" fine particles. This requires redefining the designated sieves for the analysis of Bailey fine mixes. The sizes for the designated sieves for fine Bailey mixes are shown in Table 2.7.

Table 2.7 Bailey Fine Graded Mixture Control Sieves

\begin{tabular}{|c|c|c|c|c|c|c|}
\cline { 2 - 7 } \multicolumn{1}{c|}{} & \multicolumn{7}{c|}{ NMPS, mm } & $\mathbf{1 9 . 5}$ \\
\hline DESIGNATED SIEVES & $\mathbf{3 7 . 5}$ & $\mathbf{2 5 . 0}$ & $\mathbf{1 9 . 0}$ & $\mathbf{1 2 . 5}$ & $\mathbf{9 . 5}$ & $\mathbf{4 . 7 5}$ \\
\hline Original PCS & 9.5 & 4.75 & 4.75 & 2.36 & 2.36 & 1.18 \\
\hline New Half Sieve & 4.75 & 2.36 & 2.36 & 1.18 & 1.18 & 0.60 \\
\hline New PCS & 2.36 & 1.18 & 1.18 & 0.60 & 0.60 & 0.30 \\
\hline New SCS & 0.60 & 0.30 & 0.30 & 0.15 & 0.15 & 0.075 \\
\hline New TCS & 0.15 & 0.075 & 0.075 & $*$ & $*$ & $*$ \\
\hline
\end{tabular}

- Sieve size too small to be calculated - value not determined.

The coarse aggregate ratio, CA, evaluates the effect the coarse portion of the blend has on the mixture. The equation for $\mathrm{CA}$ uses the percents passing the half sieve and the primary control sieve. Changing the CA affects the way the aggregates pack together which will lead to changes in the VMA. The CA describes how the coarse aggregate is going to pack together and 
how the fine aggregate portion of the aggregate blend will fill the voids created. The calculation for $\mathrm{CA}$ is:

$C A=\frac{\left(P_{H S}-P_{P C S}\right)}{\left(100-P_{H S}\right)}$

where

$\mathrm{CA}=$ coarse aggregate ratio

$\mathrm{P}_{\mathrm{HS}}=$ percent passing the half sieve (new half sieve for Bailey fine blend)

$\mathrm{P}_{\mathrm{PSC}}=$ percent passing the Bailey primary control sieve (new PSC for Bailey fine blend)

The coarse portion of fine aggregate ratio, $\mathrm{FA}_{\mathrm{c}}$, fills the voids created by the coarse

portion of the blend. The $\mathrm{FA}_{\mathrm{c}}$ describes how the coarse portion of the fine aggregate is going to pack together and how the aggregate is going to create voids that will be filled by the fine portion of the fine aggregate. The calculation for the $\mathrm{FA}_{\mathrm{c}}$ is:

$F A_{c}=\frac{P_{S C S}}{P_{P C S}}$

where

$\mathrm{FA}_{\mathrm{c}}=$ ratio of coarse portion of fine aggregate

$\mathrm{P}_{\mathrm{SCS}}=$ percent passing the secondary control sieve (new SCS for Bailey fine blend)

$\mathrm{P}_{\mathrm{PSC}}=$ percent passing the Bailey primary control sieve (new PSC for Bailey fine blend)

The fine portion of fine aggregate ratio, $\mathrm{FA}_{\mathrm{f}}$, fills the voids created by the coarse portion of the fine aggregate of the overall blend. The $\mathrm{FA}_{\mathrm{f}}$ also describes the remaining voids in the overall fine aggregate blend from the small voids it creates. The calculation for the $\mathrm{FA}_{\mathrm{f}}$ ratio is:

$$
F A_{f}=\frac{P_{T C S}}{P_{S C S}}
$$

where 
$\mathrm{FA}_{\mathrm{f}}=$ ratio of fine portion of fine aggregate

$\mathrm{P}_{\mathrm{TSC}}=$ percent passing the Bailey tertiary control sieve (new TSC for Bailey fine blend)

$\mathrm{P}_{\mathrm{SCS}}=$ percent passing the secondary control sieve (new SCS for Bailey fine blend)

The equations for the three aggregate ratios are based on the values of percent passing each sieve size. The percent passing the designated sieves are used in the ratios in Equations 2.7, 2.8, and 2.9. Table 2.8 and 2.9 summarize the calculations for the aggregate ratios based on the nominal maximum aggregate size and type of blend.

Table 2.8 Aggregate Ratios for Coarse and SMA Graded Mixtures

\begin{tabular}{|c|c|c|c|}
\hline \multirow{2}{*}{ NMPS, mm } & \multicolumn{3}{|c|}{ Ratio } \\
\hline & CA & $\mathbf{F A}_{\mathrm{c}}$ & $\mathbf{F A}_{\mathrm{f}}$ \\
\hline 37.5 & $\frac{\underline{\mathrm{P}}_{19}-\underline{\mathrm{P}}_{9.5}}{100-\mathrm{P}_{19}}$ & $\frac{\mathrm{P}_{2.36}}{\mathrm{P}_{9.5}}$ & $\begin{array}{l}\underline{\mathrm{P}}_{0.60} \\
\mathrm{P}_{2.36}\end{array}$ \\
\hline 25.0 & $\frac{\underline{\mathrm{P}}_{12.5}-\underline{\mathrm{P}}_{4.75}}{100-\mathrm{P}_{12.5}}$ & $\begin{array}{l}\underline{P}_{1.18} \\
P_{4.75}\end{array}$ & $\begin{array}{l}\underline{\mathrm{P}}_{0.30} \\
\mathrm{P}_{1.18}\end{array}$ \\
\hline 19.0 & $\frac{\underline{\mathrm{P}}_{9.5}}{100-\mathrm{P}_{4.75}}$ & $\begin{array}{l}\underline{P}_{1.18} \\
P_{4.75}\end{array}$ & $\frac{\underline{\mathrm{P}}_{0.30}}{\mathrm{P}_{1.18}}$ \\
\hline 12.5 & $\frac{\underline{P}_{4.75}-P_{2.36}}{100-P_{4.75}}$ & $\begin{array}{l}\underline{\mathrm{P}}_{0.60} \\
\mathrm{P}_{2.36}\end{array}$ & $\begin{array}{l}\underline{\mathrm{P}}_{0.15} \\
\mathrm{P}_{0.60}\end{array}$ \\
\hline 9.5 & $\frac{\underline{P}_{4.75}-\underline{P}_{2.36}}{100-P_{4.75}}$ & $\begin{array}{l}\underline{P}_{0.60} \\
P_{2.36}\end{array}$ & $\frac{\underline{\mathrm{P}}_{0.15}}{\mathrm{P}_{0.60}}$ \\
\hline 4.75 & $\frac{\underline{P}_{2.36}-\underline{P}_{1.18}}{100-P_{2.36}}$ & $\begin{array}{l}\underline{P}_{0.30} \\
P_{1.18}\end{array}$ & $\begin{array}{l}\underline{\mathrm{P}}_{0.075} \\
\mathrm{P}_{0.30}\end{array}$ \\
\hline
\end{tabular}

$\mathbf{P}_{\mathbf{i}}=$ indicates percent passing sieve size $\mathrm{i}$ 
Table 2.9 Aggregate Ratios for Fine Graded Mixtures

\begin{tabular}{|c|c|c|c|}
\hline \multirow{2}{*}{ NMPS, mm } & \multicolumn{3}{|c|}{ Ratio } \\
\hline & CA & $\mathbf{F A}_{\mathrm{c}}$ & $\mathbf{F A}_{\mathbf{f}}$ \\
\hline 37.5 & $\begin{array}{l}\underline{\mathrm{P}}_{4.75}-\mathrm{P}_{2.36} \\
100-\mathrm{P}_{4.75}\end{array}$ & $\frac{\mathrm{P}_{0.60}}{\mathrm{P}_{2.36}}$ & $\frac{\mathrm{P}_{0.15}}{\mathrm{P}_{0.60}}$ \\
\hline 25.0 & $\underline{\mathrm{P}}_{2.36}-\mathrm{P}_{1.18}$ & $\begin{array}{l}\underline{\mathrm{P}}_{0.30} \\
\mathrm{P}_{1.18}\end{array}$ & $\begin{array}{l}\underline{\mathrm{P}}_{0.075} \\
\mathrm{P}_{0.30}\end{array}$ \\
\hline 19.0 & $\frac{\mathrm{P}_{2.36}-\underline{\mathrm{P}}_{1.18}}{100-\mathrm{P}_{2.36}}$ & $\frac{\underline{P}_{0.30}}{\mathrm{P}_{1.18}}$ & $\frac{\underline{P}_{0.075}}{P_{0.30}}$ \\
\hline 12.5 & $\begin{array}{l}\underline{\mathrm{P}}_{1.18}-\underline{\mathrm{P}}_{0.60} \\
100-\mathrm{P}_{1.18}\end{array}$ & $\begin{array}{l}\underline{\mathrm{P}}_{0.15} \\
\mathrm{P}_{0.60}\end{array}$ & $* *$ \\
\hline 9.5 & $\underline{\mathrm{P}_{1.18}}-\mathrm{P}_{0.60}$ & $\frac{\mathrm{P}_{0.15}}{\mathrm{P}_{0.60}}$ & $* *$ \\
\hline 4.75 & $\begin{array}{l}\underline{\mathrm{P}}_{0.60}-\underline{\mathrm{P}}_{0.30} \\
100-\mathrm{P}_{0.60}\end{array}$ & $\begin{array}{l}\underline{\mathrm{P}}_{0.075} \\
\mathrm{P}_{0.30} \\
\end{array}$ & $* *$ \\
\hline
\end{tabular}

$\mathbf{P}_{\mathbf{i}}=$ indicates percent passing sieve size

** Sieve size too small to be calculated - value not determined.

The values for the three aggregate ratios indicate different characteristics of the asphalt mixture. The CA ratio affects the VMA and construction problems. A low CA ratio indicates that the mix is prone to segregation of the coarse aggregate. Segregation is a result of the coarse aggregate clustering in one particular area creating an excess of coarse aggregate in one area and a lack of coarse aggregate in another area. This will decrease the service life of an asphalt pavement. The fine aggregate ratios also indicate changes in the VMA of the mixture.

Recommended ranges for the three aggregate ratios are shown in Tables 2.10 according to coarse and fine gradation type and Table 2.11 shows the recommended ratios for SMA mixtures (Vavrik, et. al., 2002).

Table 2.10 Recommended Ranges of Aggregate Ratios for Coarse and Fine Mixtures

\begin{tabular}{|c|c|c|c|c|c|c|}
\cline { 2 - 7 } \multicolumn{1}{c|}{} & \multicolumn{7}{c|}{ NMPS, mm } \\
\cline { 2 - 7 } \multicolumn{1}{c|}{} & $\mathbf{3 7 . 5}$ & $\mathbf{2 5 . 0}$ & $\mathbf{1 9 . 0}$ & $\mathbf{1 2 . 5}$ & $\mathbf{9 . 5}$ & $\mathbf{4 . 7 5}$ \\
\hline CA (Bailey Coarse Blend) & $0.80-0.95$ & $0.70-0.85$ & $0.60-0.75$ & $0.50-0.65$ & $0.40-0.55$ & $0.30-0.45$ \\
\hline CA (Bailey Fine Blend) & $0.60-1.00$ & $0.60-1.00$ & $0.60-1.00$ & $0.60-1.00$ & $0.60-1.00$ & $0.60-1.00$ \\
\hline FA $_{\mathbf{c}}$ & $0.35-0.50$ & $0.35-0.50$ & $0.35-0.50$ & $0.35-0.50$ & $0.35-0.50$ & $0.35-0.50$ \\
\hline FA $_{\mathbf{f}}$ & $0.35-0.50$ & $0.35-0.50$ & $0.35-0.50$ & $0.35-0.50$ & $0.35-0.50$ & $0.35-0.50$ \\
\hline
\end{tabular}




\section{Table 2.11 Recommended Ranges of Aggregate Ratios for SMA Mixtures}

\begin{tabular}{|c|c|c|c|}
\cline { 2 - 4 } \multicolumn{1}{c|}{} & \multicolumn{3}{c|}{ NMPS, $\mathbf{~ m m}$} \\
\cline { 2 - 4 } \multicolumn{1}{c|}{ CA } & $\mathbf{1 9 . 0}$ & $\mathbf{1 2 . 5}$ & $\mathbf{9 . 5}$ \\
\hline FA $_{\mathbf{c}}$ & $0.35-0.50$ & $0.25-0.40$ & $0.15-0.30$ \\
\hline FA $_{\mathbf{f}}$ & $0.60-0.85$ & $0.60-0.85$ & $0.60-0.85$ \\
\hline & $0.65-0.90$ & $0.60-0.85$ & $0.60-0.85$ \\
\hline
\end{tabular}

\subsubsection{Effects on VMA}

The Bailey Method has four basic parameters which relate to changes in VMA. The four parameters are the percent chosen unit weight, $\mathrm{CA}, \mathrm{FA}_{\mathrm{c}}$, and $\mathrm{FA}_{\mathrm{f}}$. The effect that each parameter has on the VMA is dependent on whether the aggregate blend is considered a coarse blend or a fine blend by Bailey's definition. Table 2.12 displays the general effect on the VMA based on changes in the four parameters (Vavrik, et. al., 2002).

\section{Table 2.12 Effects of Increasing Bailey Parameters on VMA}

\begin{tabular}{|c|c|c|c|}
\hline Parameter & Coarse Blend & Fine Blend & SMA \\
\hline Percent Chosen Unit Weight & increases & decreases & increases \\
\hline $\mathrm{CA}$ & increases & increases & increases \\
\hline $\mathrm{FA}_{\mathrm{c}}$ & decreases & decreases & decreases \\
\hline $\mathrm{FA}_{\mathrm{f}}$ & decreases & decreases & decreases \\
\hline
\end{tabular}

As seen in Table 2.12, the increasing percent chosen unit weight results in an increase in VMA of Bailey coarse blends and a decrease in VMA for Bailey fine blends. Therefore, the minimum VMA predicted by the Bailey Method should be located at the separation between Bailey coarse and Bailey fine mixtures. The separation point is a chosen unit weight of 90 percent. Figure 2.5 shows the relationship between the change in chosen unit weight and the effect it has on the VMA. The figure shows the minimum predicted VMA value as the mix changes from coarse to fine. The percent chosen unit weight values less than or equal to 90 represent the fine mixtures while the values 95 to 105 represent the coarse mixtures. The values 
greater than or equal to 110 represent the SMA mixtures. The region from 90 to 95 should be avoided to prevent high probability of the mixture transferring in and out of coarse aggregate interlock. Mixtures above and below the transition zone ${ }^{3}$ between coarse and fine will perform more predictably to slight variations in the gradation of the mixture (Aurilio, et. al., 2002).

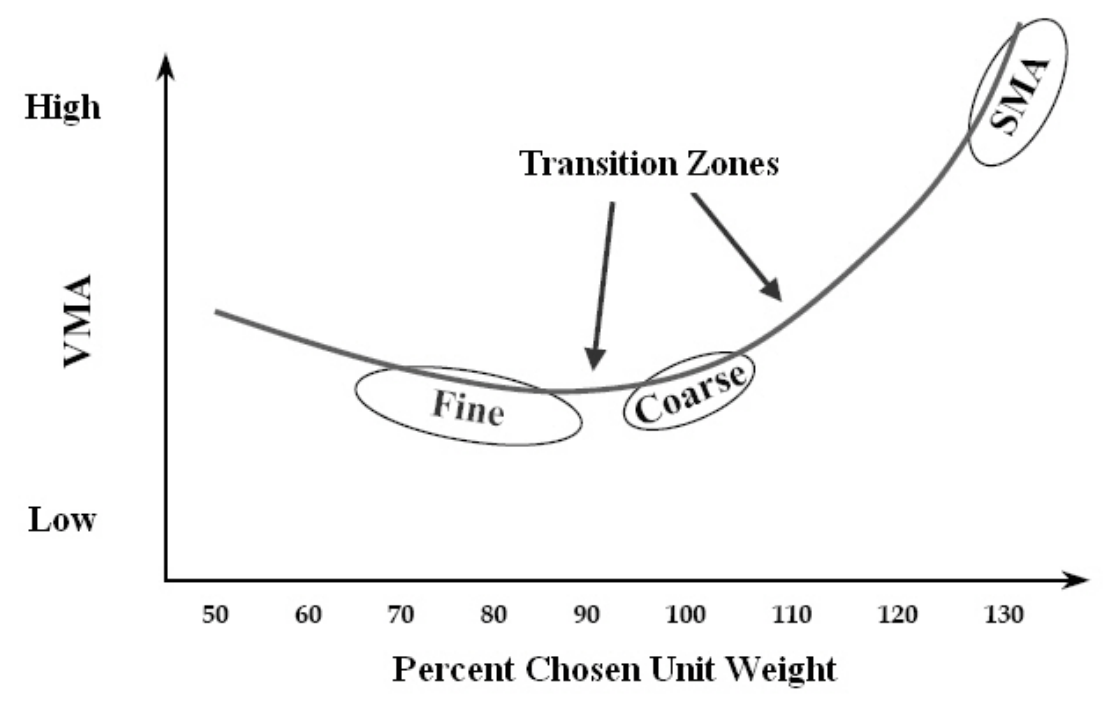

Figure 2.5 Chosen Unit Weight vs. Change in VMA

The magnitude of change in VMA is also dependent on whether the aggregate blend is a coarse blend or a fine blend according to Bailey. The change in value of the Bailey parameters that result in a $1 \%$ change in VMA is presented in Table 2.13. The VMA will be adjusted according to Table 2.12.

Table 2.13 Change in Value of Bailey Parameter to Produce 1\% Change in VMA

\begin{tabular}{|c|c|c|}
\cline { 2 - 3 } \multicolumn{1}{c|}{} & \multicolumn{2}{c|}{ Change in Parameter } \\
\cline { 2 - 3 } \multicolumn{1}{c|}{} & Coarse Blend & Fine Blend \\
\hline Chosen Percent Unit Weight & $4 \%$ change in Bailey PCS & $6 \%$ change in Bailey PCS \\
\hline CA & 0.20 & 0.35 \\
\hline AA $_{\mathbf{c}}$ & 0.05 & 0.05 \\
\hline FA $_{\mathbf{f}}$ & 0.05 & 0.05 \\
\hline
\end{tabular}

\footnotetext{
${ }^{3}$ The term transition zone is introduced to describe the area between the different zones for the mix types.
} 


\section{CHAPTER 3: RESEARCH METHODOLOGY}

\subsection{INTRODUCTION}

This research evaluated VMA laboratory results compared to the values predicted by the Bailey Method. Laboratory asphalt concrete samples were created and volumetric analysis was performed. The values for VMA were then analyzed versus the results predicted for the Bailey Method. The experiment used two mix designs from each of two contractors. Each mix design was altered into a coarse and a fine mixture. The contractor's mix, coarse mix, and fine mix were each evaluated at three asphalt contents. The factors and levels used in the experiment were:

\begin{tabular}{l|l} 
Factors & Levels \\
\hline Mix type & Greer -9.5 and $19 \mathrm{~mm}$ SuperPave \\
WV Paving $-9.5 \mathrm{~mm}$ SuperPave, Wearing I Marshall \\
Gradation & $\begin{array}{l}\text { Contractor, Fine, Coarse } \\
\text { Design, Low, High }\end{array}$
\end{tabular}

The parameters for each sample are shown in Table 3.1.

\subsection{TYPES}

The aggregate used for this research was provided by two suppliers, Greer Industries, Morgantown, WV and West Virginia Paving Company, Dunbar, WV. Greer industries provided aggregates for a $9.5 \mathrm{~mm}$ and $19 \mathrm{~mm}$ SuperPave mix and West Virginia Paving provided a $9.5 \mathrm{~mm}$ SuperPave mix and a Wearing I Marshall mix. The aggregate for the SuperPave designs was crushed limestone aggregate while the aggregate for the Marshall design was \#8 crushed gravel. The aggregates obtained were air dried and sieved according to the following sieve sizes: $19 \mathrm{~mm}, 12.5 \mathrm{~mm}, 9.5 \mathrm{~mm}, 4.75 \mathrm{~mm}, 2.36 \mathrm{~mm}, 1.18 \mathrm{~mm}, 0.6 \mathrm{~mm}, 0.3 \mathrm{~mm}$, and $0.075 \mathrm{~mm}$. The material passing the $0.075 \mathrm{~mm}$ sieve was kept as dust material. Extra bag house fines 
Table 3.1 Sample Combinations

\begin{tabular}{|c|c|c|c|c|}
\hline Sample & Contractor & Mix Type & Gradation & Percent Binder \\
\hline 1 & Greer & 9.5 & Coarse & 4.6 \\
\hline 2 & Greer & 9.5 & Coarse & 5.1 \\
\hline 3 & Greer & 9.5 & Coarse & 5.6 \\
\hline 4 & Greer & 9.5 & Contractor & 5.2 \\
\hline 5 & Greer & 9.5 & Contractor & 5.7 \\
\hline 6 & Greer & 9.5 & Contractor & 6.2 \\
\hline 7 & Greer & 9.5 & Fine & 6.2 \\
\hline 8 & Greer & 9.5 & Fine & 6.7 \\
\hline 9 & Greer & 9.5 & Fine & 7.2 \\
\hline 10 & Greer & 19 & Coarse & 4.0 \\
\hline 11 & Greer & 19 & Coarse & 4.5 \\
\hline 12 & Greer & 19 & Coarse & 5.0 \\
\hline 13 & Greer & 19 & Contractor & 4.3 \\
\hline 14 & Greer & 19 & Contractor & 4.8 \\
\hline 15 & Greer & 19 & Contractor & 5.3 \\
\hline 16 & Greer & 19 & Fine & 4.7 \\
\hline 17 & Greer & 19 & Fine & 5.2 \\
\hline 18 & Greer & 19 & Fine & 5.7 \\
\hline 19 & WV Paving & 9.5 & Coarse & 4.5 \\
\hline 20 & WV Paving & 9.5 & Coarse & 5.0 \\
\hline 21 & WV Paving & 9.5 & Coarse & 5.5 \\
\hline 22 & WV Paving & 9.5 & Contractor & 5.4 \\
\hline 23 & WV Paving & 9.5 & Contractor & 5.9 \\
\hline 24 & WV Paving & 9.5 & Contractor & 6.4 \\
\hline 25 & WV Paving & 9.5 & Fine & 5.8 \\
\hline 26 & WV Paving & 9.5 & Fine & 6.3 \\
\hline 27 & WV Paving & 9.5 & Fine & 6.8 \\
\hline 28 & WV Paving & Wearing I & Coarse & 4.5 \\
\hline 29 & WV Paving & Wearing I & Coarse & 5.0 \\
\hline 30 & WV Paving & Wearing I & Coarse & 5.5 \\
\hline 31 & WV Paving & Wearing I & Contractor & 5.2 \\
\hline 32 & WV Paving & Wearing I & Contractor & 5.7 \\
\hline 33 & WV Paving & Wearing I & Contractor & 6.2 \\
\hline 34 & WV Paving & Wearing I & Fine & 6.4 \\
\hline 35 & WV Paving & Wearing I & Fine & 6.9 \\
\hline 36 & WV Paving & Wearing I & Fine & 7.4 \\
\hline
\end{tabular}

were provided by Greer Industries and were used as additional dust material when needed. All aggregates were then washed to remove excess dust material, dried and stored in separate bins according to size. 


\subsection{AGGREGATE BLENDS}

For each of the four mixes from the contractors, three blends were used during the experiment:

- Contractor blend - these are classified as fine mixes according to the Bailey Method.

- Coarse blend - the stockpile blends were altered to produce the coarsest possible mix while remaining within the SuperPave and Marshall control points. These are classified as coarse mixes according to the Bailey Method.

- Fine blend - the stockpile blends were altered to produce the finest possible mix while remaining within the SuperPave and Marshall control points and with the percent passing the SuperPave primary control sieve being less than the criteria for a SuperPave coarse mix. Hence, these mixes would be classified as coarse mixes by the SuperPave method, but are classified as fine mixes according to the Bailey Method.

The experimental blends are presented in Tables 3.2 and 3.3, and Figures 3.1 to 3.4. The percent chosen unit weights for each design are shown in Table 3.4.

Table 3.2 Greer Asphalt Aggregate Gradations

\begin{tabular}{|c|c|c|c|c|c|c|}
\cline { 2 - 7 } \multicolumn{1}{c|}{} & \multicolumn{7}{c|}{ Greer Asphalt } \\
\cline { 2 - 7 } \multicolumn{1}{c|}{} & \multicolumn{2}{c|}{$\mathbf{9 . 5 m m}$ SuperPave } & \multicolumn{2}{c|}{ 19mm SuperPave } \\
\cline { 2 - 7 } & $\begin{array}{c}\text { Contractor } \\
\text { Mix }\end{array}$ & $\begin{array}{c}\text { Coarse } \\
\text { Mix }\end{array}$ & $\begin{array}{c}\text { Fine } \\
\text { Mix }\end{array}$ & $\begin{array}{c}\text { Contractor } \\
\text { Mix }\end{array}$ & $\begin{array}{c}\text { Coarse } \\
\text { Mix }\end{array}$ & $\begin{array}{c}\text { Fine } \\
\text { Mix }\end{array}$ \\
\hline Sieve Size (mm) & & & & & & \\
\hline $\mathbf{2 5 . 0}$ & 100 & 100 & 100 & 100 & 100 & 100 \\
\hline $\mathbf{1 9 . 0}$ & 100 & 100 & 100 & 96 & 96 & 96 \\
\hline $\mathbf{1 2 . 5}$ & 100 & 100 & 100 & 72 & 68 & 74 \\
\hline $\mathbf{9 . 5}$ & 96 & 95 & 97 & 58 & 52 & 61 \\
\hline $\mathbf{4 . 7 5}$ & 62 & 55 & 69 & 42 & 34 & 46 \\
\hline $\mathbf{2 . 3 6}$ & 37 & 32 & 43 & 31 & 25 & 34 \\
\hline $\mathbf{1 . 1 8}$ & 23 & 19 & 26 & 19 & 16 & 21 \\
\hline $\mathbf{0 . 6 0 0}$ & 15 & 12 & 17 & 12 & 10 & 13 \\
\hline $\mathbf{0 . 3 0 0}$ & 10 & 9 & 11 & 8 & 7 & 9 \\
\hline $\mathbf{0 . 0 7 5}$ & 4.5 & 4.0 & 5.1 & 4.5 & 4.2 & 4.7 \\
\hline
\end{tabular}


Table 3.3 West Virginia Paving Aggregate Gradations

\begin{tabular}{|c|c|c|c|c|c|c|}
\cline { 2 - 7 } \multicolumn{1}{c|}{} & \multicolumn{6}{c|}{ West Virginia Paving } \\
\cline { 2 - 7 } & \multicolumn{3}{c|}{ 9.5mm SuperPave } & \multicolumn{3}{c|}{ Wearing I Marshall } \\
\cline { 2 - 7 } & $\begin{array}{c}\text { Contractor } \\
\text { Mix }\end{array}$ & $\begin{array}{c}\text { Coarse } \\
\text { Mix }\end{array}$ & $\begin{array}{c}\text { Fine } \\
\text { Mix }\end{array}$ & $\begin{array}{c}\text { Contractor } \\
\text { Mix }\end{array}$ & $\begin{array}{c}\text { Coarse } \\
\text { Mix }\end{array}$ & $\begin{array}{c}\text { Fine } \\
\text { Mix }\end{array}$ \\
\hline Sieve Size (mm) & & & & & & \\
\hline $\mathbf{1 2 . 5}$ & 100 & 100 & 100 & 100 & 100 & 100 \\
\hline $\mathbf{9 . 5}$ & 98 & 96 & 98 & 95 & 94 & 97 \\
\hline $\mathbf{4 . 7 5}$ & 71 & 60 & 77 & 59 & 52 & 73 \\
\hline $\mathbf{2 . 3 6}$ & 42 & 32 & 47 & 35 & 30 & 46 \\
\hline $\mathbf{1 . 1 8}$ & 25 & 19 & 28 & 25 & 22 & 34 \\
\hline $\mathbf{0 . 6 0 0}$ & 16 & 12 & 18 & 17 & 15 & 23 \\
\hline $\mathbf{0 . 3 0 0}$ & 10 & 8 & 11 & 9 & 7 & 11 \\
\hline $\mathbf{0 . 0 7 5}$ & 4.6 & 3.8 & 5.0 & 4.9 & 4.2 & 6.1 \\
\hline
\end{tabular}

Table 3.4 Percent Chosen Unit Weight of Each Mixture

\begin{tabular}{|c|c|c|c|c|c|c|}
\cline { 2 - 7 } & \multicolumn{6}{|c|}{ Greer Asphalt } \\
\cline { 2 - 7 } & \multicolumn{3}{|c|}{$\mathbf{9 . 5 m m}$} & \multicolumn{3}{c|}{ 19mm } \\
\cline { 2 - 7 } & Contractor & Coarse & Fine & Contractor & Coarse & Fine \\
\hline $\begin{array}{c}\text { Percent ChosenUnit } \\
\text { Weight }\end{array}$ & 85 & 98 & 73 & 89 & 105 & 80 \\
\hline
\end{tabular}

\begin{tabular}{|c|c|c|c|c|c|c|}
\cline { 2 - 7 } & \multicolumn{6}{c|}{ West Virginia Paving } \\
\cline { 2 - 7 } & \multicolumn{3}{|c|}{ 9.5mm } & \multicolumn{4}{c|}{ Wearing I } \\
\cline { 2 - 7 } & Contractor & Coarse & Fine & Contractor & Coarse & Fine \\
\hline $\begin{array}{c}\text { Percent Chosen Unit } \\
\text { Weight }\end{array}$ & 75 & 99 & 64 & 84 & 96 & 60 \\
\hline
\end{tabular}




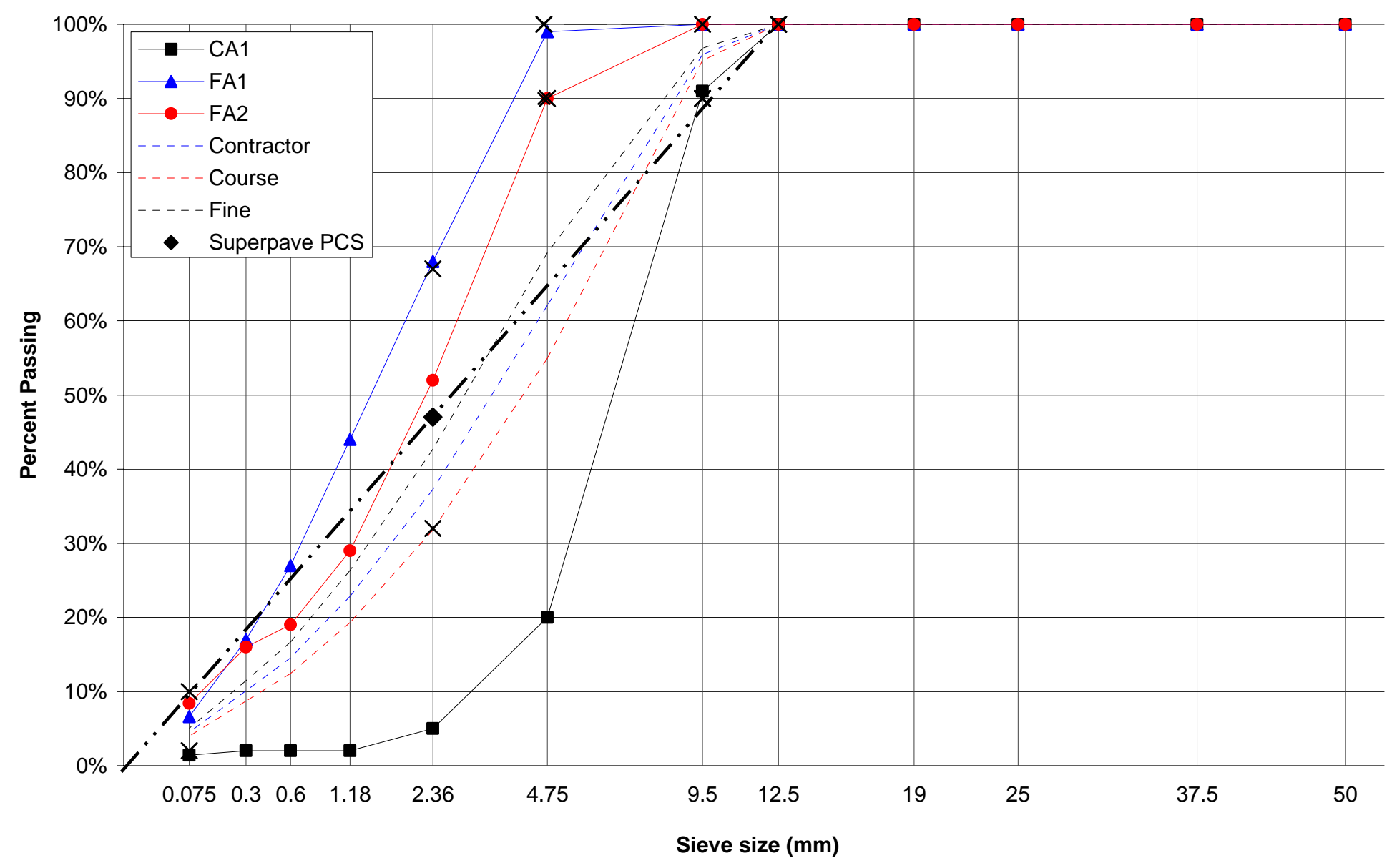

Figure 3.1 Gradation Chart for Greer 9.5mm Aggregate 


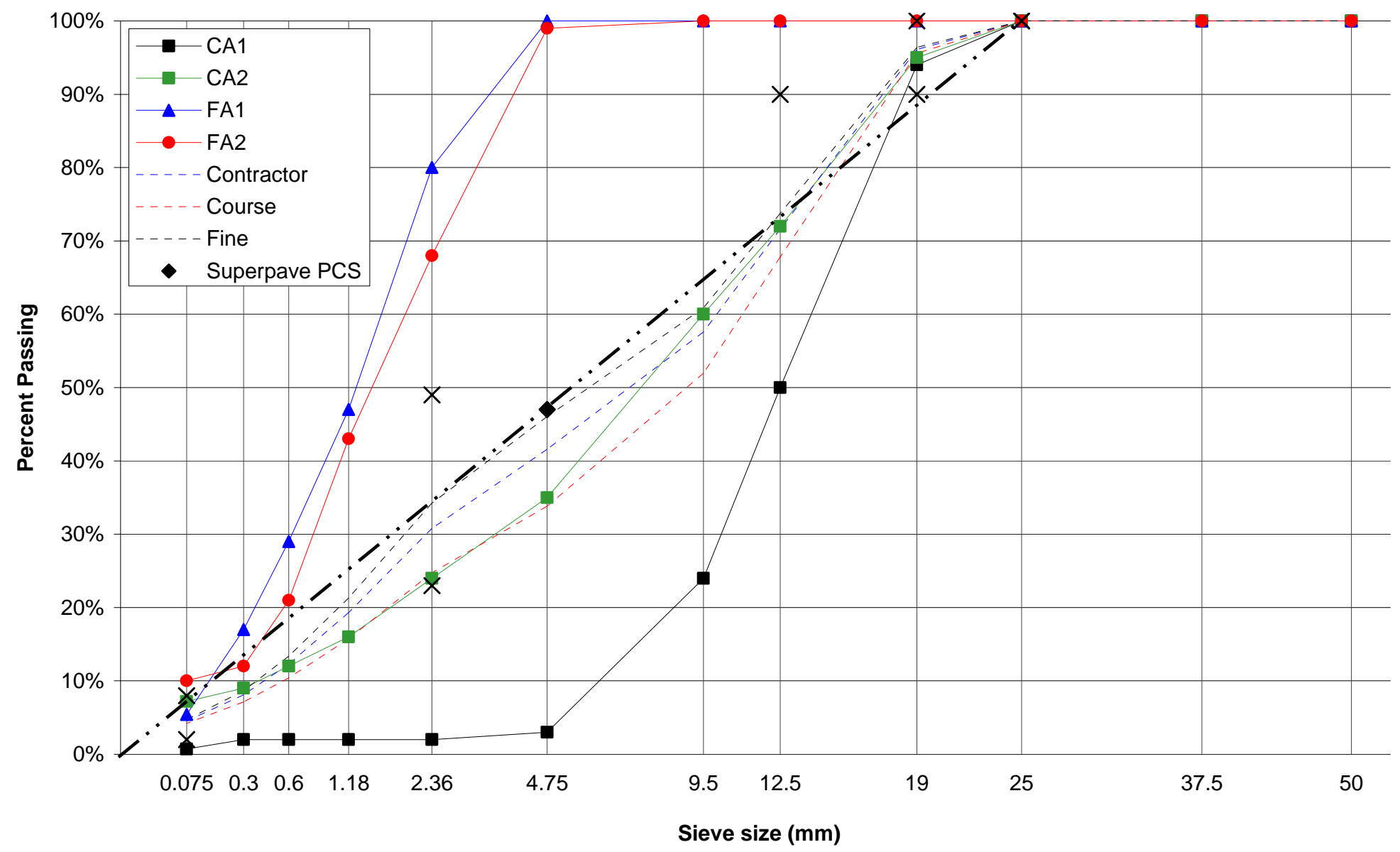

Figure 3.2 Gradation Chart for Greer 19mm Aggregate 


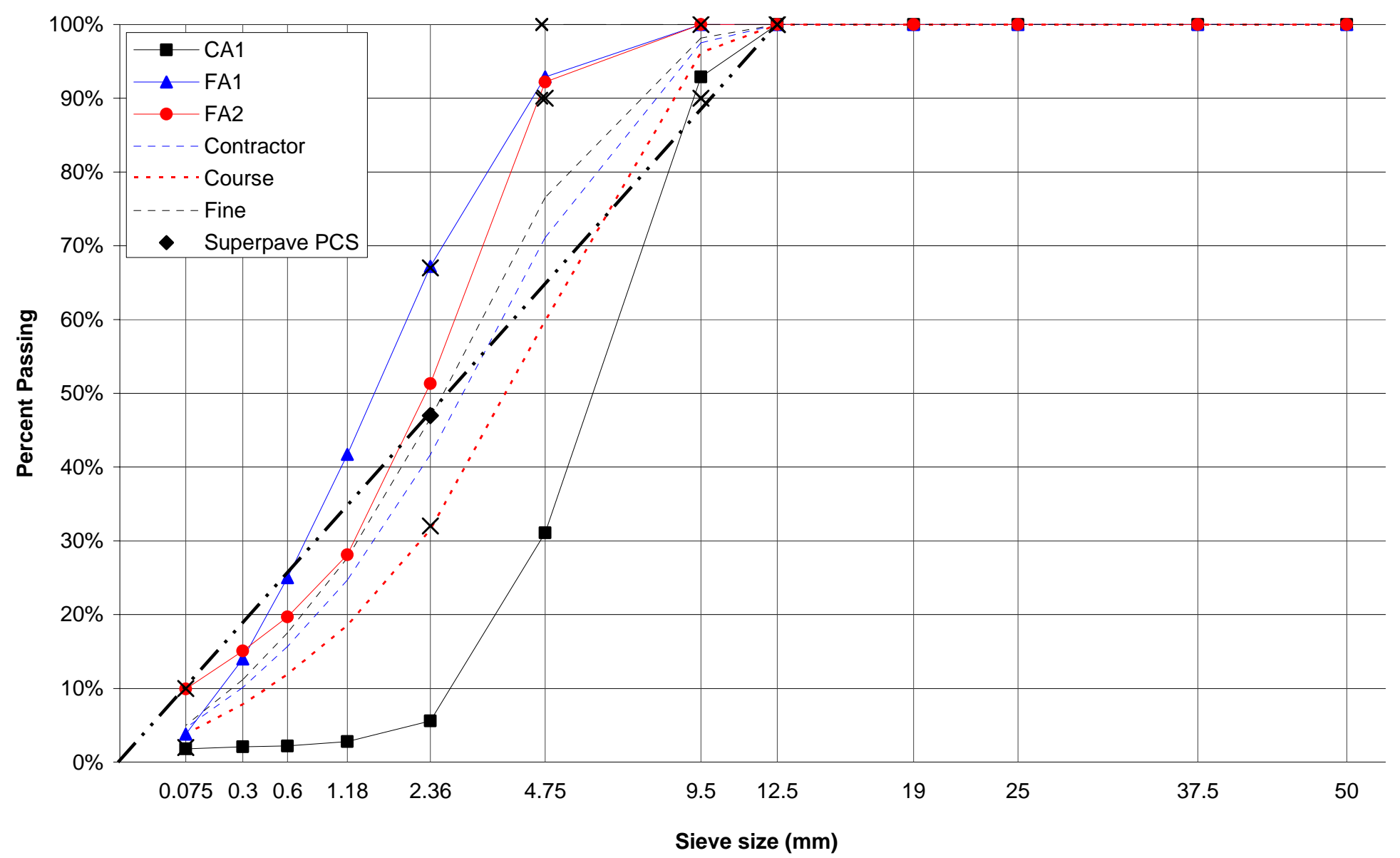

Figure 3.3 Gradation Chart for West Virginia Paving 9.5mm Aggregate 


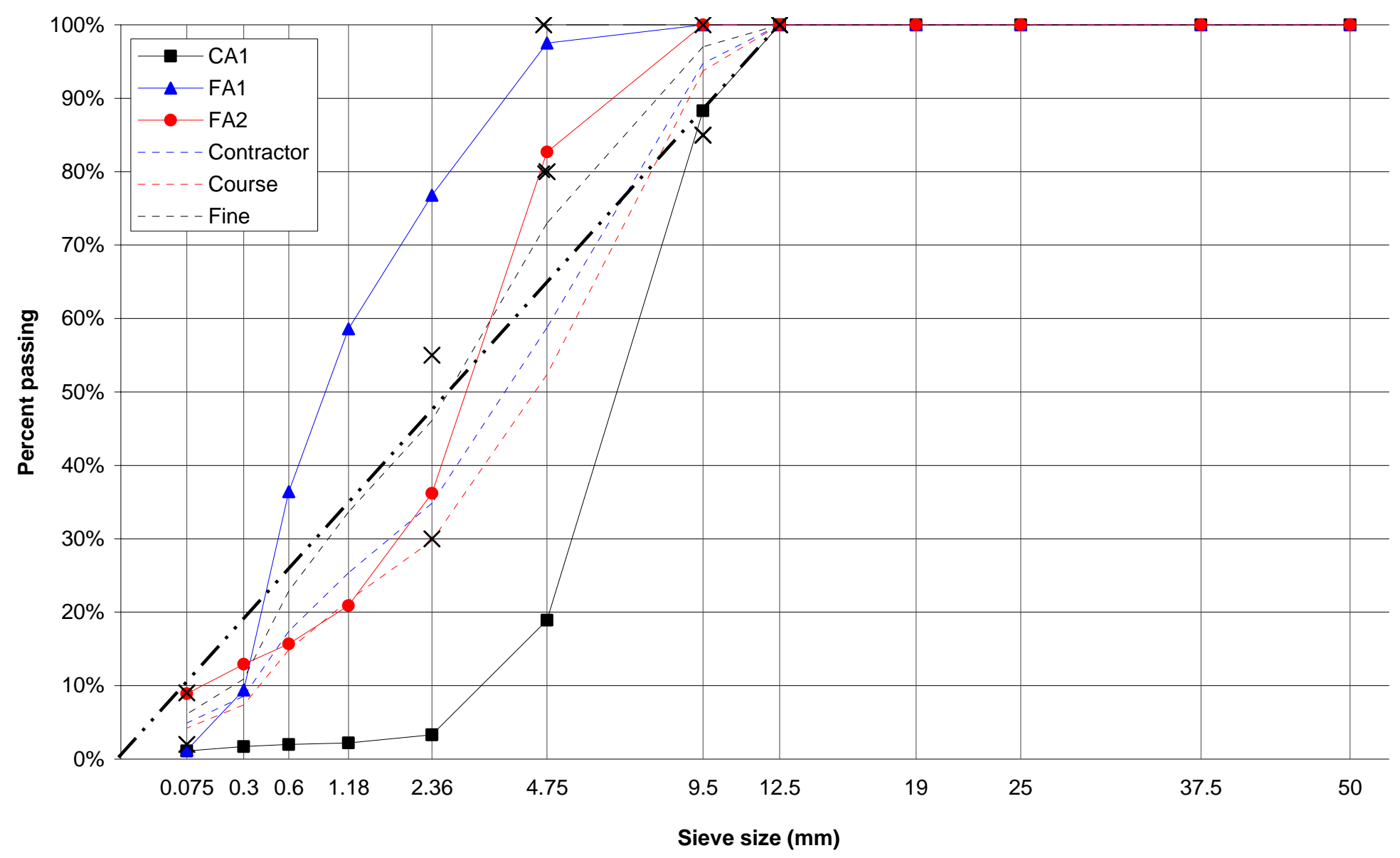

Figure 3.4 Gradation Chart for West Virginia Paving Wearing I Aggregate 


\subsection{UNIT WEIGHT OF AGGREGATE}

The rodded and loose unit weights of the aggregate were determined according to AASHTO T19 Method for Determining the Unit Weight and Voids in Aggregate. The method requires a specific bucket size for each nominal maximum aggregate size to perform the unit weight experiment. The volume of the bucket used for the coarse and fine aggregate conformed to recommendations for the Bailey Method (Pine, 2005). The buckets and tamping rod were fabricated by Wilson Works of Morgantown, WV. The volume of the two buckets was tested by filling them with water to the top edge of the bucket and covering them with a glass plate and water temperature of $77^{\circ} \mathrm{F}$. The volume of the water was then calculated by subtracting the mass of the empty bucket from the mass of the bucket filled with water to determine the volume of the bucket for the unit weight calculations. The bucket volume used for the coarse aggregate unit weight was $0.00705 \mathrm{~m}^{3}$ and the bucket volume for the fine aggregate unit weight was $0.000965 \mathrm{~m}^{3}$.

\subsection{PERCENT BINDER}

The percent asphalt binder selected for each mixture was determined by controlling the asphalt film thickness. VMA is the mix design parameter that controls asphalt film thickness. This is the reason that the film thickness was held constant for this research. By holding the asphalt film thickness constant, the change in VMA should be a result of the change in gradation and not the varying asphalt film thickness.

A target asphalt content was determined for each mixture according to constant asphalt film thickness and from that value a high percent binder and low percent binder were determined by adjusting the target percent binder $\pm 0.5 \%$. Therefore, for each mixture there was a target asphalt content, high asphalt content, and a low asphalt content. The target asphalt content was 
determined by using the asphalt content used by the contractor. Therefore, when the gradation of the contractor's mix design was altered to a coarse and fine mix, the asphalt content was adjusted to maintain constant asphalt film thickness. Equation 2.5 and the surface area factors from Zaniewski and Reyes (2003) were used to determine the target asphalt content for constant film thickness. The resulting asphalt contents for each of the mixes are shown in Tables 3.5 and 3.6.

Table 3.5 Asphalt Contents for Greer Mixes

\begin{tabular}{|c|c|c|c|c|c|c|}
\cline { 2 - 7 } \multicolumn{1}{c|}{} & \multicolumn{5}{c|}{ 9.5mm } & \multicolumn{2}{c|}{ 19mm } \\
\cline { 2 - 7 } \multicolumn{1}{c|}{} & \multicolumn{3}{c|}{ Greer } \\
\hline $\begin{array}{c}\text { Asphalt } \\
\text { Content }\end{array}$ & Coarse & Contractor & Fine & Coarse & Contractor & Fine \\
\hline Low & 4.6 & 5.2 & 5.8 & 3.6 & 3.9 & 4.1 \\
\hline Target & 5.1 & 5.7 & 6.3 & 4.1 & 4.4 & 4.6 \\
\hline High & 5.6 & 6.2 & 6.8 & 4.6 & 4.9 & 5.1 \\
\hline
\end{tabular}

\section{Table 3.6 Asphalt Contents for West Virginia Paving Mixes}

\begin{tabular}{|c|c|c|c|c|c|c|}
\hline \multirow[b]{3}{*}{$\begin{array}{l}\text { Asphalt } \\
\text { Content }\end{array}$} & \multicolumn{6}{|c|}{ West Virginia Paving } \\
\hline & \multicolumn{3}{|c|}{$9.5 \mathrm{~mm}$} & \multicolumn{3}{|c|}{ Wearing I } \\
\hline & Coarse & Contractor & Fine & Coarse & Contractor & Fine \\
\hline Low & 4.5 & 5.4 & 5.8 & 4.5 & 5.2 & 6.4 \\
\hline Target & 5.0 & 5.9 & 6.3 & 5.0 & 5.7 & 6.9 \\
\hline High & 5.5 & 6.4 & 6.8 & 5.5 & 6.2 & 7.4 \\
\hline
\end{tabular}

\subsection{MIXTURE PREPARATION}

Once the blend gradations were selected, weigh out tables were created to properly blend the individual aggregates for the various gradation types. The proper portions of aggregate and asphalt binder for each mix design were heated to the upper limit of the mix temperature range for the asphalt binder type. The mixing and compaction temperatures for each binder grade are shown in the Table 3.7 (Marathon Ashland, 2006). Once at the required temperature the 
aggregate and binder were mixed in a bucket mixer. Each batch of material was sufficient to make two bulk specific gravity samples and one maximum theoretical specific gravity sample.

Table 3.7 Mixing and Compaction Temperatures

\begin{tabular}{|c|c|c|c|c|}
\hline \multirow{2}{*}{$\begin{array}{c}\text { Binder } \\
\text { Grade }\end{array}$} & \multicolumn{2}{|c|}{ Mixing Temp $\left({ }^{\circ} \mathrm{C}\right)$} & \multicolumn{2}{c|}{ Compaction Temp $\left({ }^{\circ} \mathrm{C}\right)$} \\
\cline { 2 - 5 } & Min & Max & Min & Max \\
\hline PG 64-22 & 150 & 157 & 140 & 145 \\
\hline PG 70-22 & 159 & 165 & 148 & 153 \\
\hline
\end{tabular}

The mixed sample was then quartered into the required masses and placed in pans for short-term aging. The sample sizes varied according to the mix type and mix design method:

- Marshall Wearing I mixes - two 1200 gram samples for $\mathrm{G}_{\mathrm{mb}}$ and one 1000 gram sample for $\mathrm{G}_{\mathrm{mm}}$

- SuperPave $9.5 \mathrm{~mm}$ mixes - two 4500 gram samples for $\mathrm{G}_{\mathrm{mb}}$ and one 1000 gram sample for $\mathrm{G}_{\mathrm{mm}}$

- SuperPave $19 \mathrm{~mm}$ mixes - two 4500 gram samples for $\mathrm{G}_{\mathrm{mb}}$ and one 1500 gram sample for $\mathrm{G}_{\mathrm{mm}}$

The samples were then placed in the oven at the compaction temperature for two hours and stirred after one hour.

The two $G_{m b}$ samples were then ready to be compacted with the gyratory compactor for the SuperPave samples and the Marshall compactor for the Marshall samples. The samples were placed into preheated molds and compacted to 100 gyrations for the SuperPave samples and 75 blows per side for the Marshall samples. The samples were allowed to cool and then the $\mathrm{G}_{\mathrm{mb}}$ samples were extracted from the mold to be analyzed for bulk specific gravity. 
The $\mathrm{G}_{\mathrm{mm}}$ samples were continually stirred at room temperature to allow the asphalt to harden without compaction effort. Then the $\mathrm{G}_{\mathrm{mm}}$ samples were analyzed for theoretical maximum specific gravity.

\subsection{BAILEY ANALYSIS}

The Bailey analysis was performed on the contractor's original mix, the coarse mix, and the fine mix to determine the aggregate ratios for those mixtures. The aggregate ratios according to Bailey for the original contractor's mix design were also evaluated and are discussed in the following subsections.

\subsubsection{Contractor's Mix Design Analysis}

The contractor's mix design according to the Bailey Method are considered to be fine mixtures because the chosen unit weight according to each design was less than or equal to 90 percent. Therefore, the criteria for the aggregate ratios must conform to the recommended ratios for the fine mixtures in the Bailey analysis. The contractors results were compared to the recommended criteria set forth by Bailey. The criteria for the aggregate ratios and the values for each contractor mix design are presented in Table 3.8.

The results of this analysis indicate that some of the contractors' mixes do not meet all the Bailey criteria (Vavrik, et. al., 2002). The Greer $19 \mathrm{~mm}$ mix has a CA higher than the recommended range. This suggests the mix is prone to horizontal deformation during compaction, allowing the mat to widen. The $\mathrm{FA}_{\mathrm{f}}$ for this mix is too high indicating the mix may be prone to low air voids and low voids in the mineral aggregate. The WV $9.5 \mathrm{~mm}$ mix has a low CA indicating the mix may be susceptible to segregation. 
Table 3.8 Recommended Bailey Aggregate Ratios and Contractors’ Ratios

\begin{tabular}{|c|c|c|c|c|c|}
\cline { 2 - 6 } \multicolumn{1}{c|}{} & Criteria & Greer 9.5mm & Greer 19mm & WV 9.5mm & WV Wearing I \\
\hline $\begin{array}{c}\text { Percent Chosen } \\
\text { Unit Weight }\end{array}$ & $\begin{array}{c}\leq 90 \% \text { (Fine) } \\
95 \%-105 \% \text { (Coarse) }\end{array}$ & $85 \%$ & $89 \%$ & $75 \%$ & $84 \%$ \\
\hline CA & $0.60-1.00$ & 0.66 & $\mathbf{1 . 2 0}$ & $\mathbf{0 . 5 3}$ & 0.80 \\
\hline FA $_{\mathbf{c}}$ & $0.35-0.50$ & 0.41 & 0.42 & 0.44 & 0.41 \\
\hline FA $_{\mathbf{f}}$ & $0.35-0.50$ & 0.47 & $\mathbf{0 . 5 6}$ & NA & NA \\
\hline
\end{tabular}

Bold values indicate results outside Bailey criteria

\subsubsection{Coarse and Fine Blends Design}

The contractors' mix designs were altered into coarse and fine blends and evaluated by the Bailey Method. The aggregate ratios were selected to conform to the recommended ratios for coarse and fine mixtures accordingly in the Bailey analysis. The coarse and fine mixture results were compared to the recommended requirements set forth by Bailey. The requirements for the aggregate ratios and the values for each contractor mix design are presented in Table 3.9 and the coarse and fine designations refer to Bailey coarse and fine blends. There are a few cases where the Bailey criteria could not be met with any combination of the available aggregates. In these cases, blends were selected to minimize the violation of the Bailey criteria. 
Table 3.9 Recommended Bailey Aggregate Ratios and Coarse and Fine Blends

\begin{tabular}{|c|c|c|c|c|c|c|}
\cline { 5 - 7 } \multicolumn{2}{c}{} & \multicolumn{4}{c|}{ Modified Greer Asphalt } \\
\cline { 5 - 7 } \multirow{2}{*}{ Parameter } & Bailey Criteria & \multirow{2}{*}{ Coarse } & \multirow{2}{*}{ Fine } & \multirow{2}{*}{ Coarse } & \multirow{2}{*}{ Fine } \\
\cline { 2 - 7 } & Coarse & Fine & & & & \\
\hline Percent Chosen Unit Weight & $95 \%-105 \%$ & $\leq 90 \%$ & $98 \%$ & $73 \%$ & $105 \%$ & $80 \%$ \\
\hline $\mathrm{CA}$ & $0.40-0.55$ & $0.60-1.00$ & 0.51 & $\mathbf{0 . 5 3}$ & $\mathbf{0 . 3 8}$ & $\mathbf{1 . 0 8}$ \\
\hline $\mathrm{FA}_{\mathrm{c}}$ & $0.35-0.50$ & $0.35-0.50$ & 0.38 & 0.47 & 0.47 & 0.43 \\
\hline $\mathrm{FA}_{\mathrm{f}}$ & $0.35-0.50$ & $0.35-0.50$ & 0.50 & $\mathrm{NA}$ & 0.44 & $\mathbf{0 . 5 2}$ \\
\hline
\end{tabular}

\begin{tabular}{|c|c|c|c|c|c|c|}
\cline { 5 - 7 } \multicolumn{2}{c|}{} & \multicolumn{3}{c|}{ Modified West Virginia Paving } \\
\cline { 5 - 7 } \multicolumn{2}{c|}{ Parameter } & Bailey Criteria & \multirow{2}{*}{ Coarse } & \multirow{2}{*}{ Fine } & \multirow{2}{*}{ Coarse } & \multirow{2}{*}{ Fine } \\
\cline { 2 - 7 } & Coarse & Fine & & & & \\
\hline Percent Chosen Unit Weight & $95 \%-105 \%$ & $\leq 90 \%$ & $99 \%$ & $64 \%$ & $96 \%$ & $60 \%$ \\
\hline $\mathrm{CA}$ & $0.40-0.55$ & $0.60-1.00$ & $\mathbf{0 . 7 0}$ & $\mathbf{0 . 5 3}$ & 0.46 & 0.92 \\
\hline $\mathrm{FA}_{\mathrm{c}}$ & $0.35-0.50$ & $0.35-0.50$ & 0.38 & 0.44 & 0.50 & 0.39 \\
\hline $\mathrm{FA}_{\mathrm{f}}$ & $0.35-0.50$ & $0.35-0.50$ & 0.50 & $\mathrm{NA}$ & 0.40 & $\mathrm{NA}$ \\
\hline
\end{tabular}

Bold values indicate results outside Bailey criteria

The calculations for the aggregate ratios were conducted to predict the magnitude of change in VMA. The aggregate ratios are also used in the Bailey analysis to indicate potential construction problems in the field. The coarse aggregate ratio is the main indicator for potential problems. If the CA ratio exceeds a value of 1.0, the mix is unbalanced and neither the large particles nor the small particles in the coarse aggregate can control the structure of the aggregate skeleton. If the CA ratio is below the recommended range based on the mix type, the blend is prone to segregation which can lead to a short pavement life (Vavrik, et. al., 2002).

The VMA changes according to the Bailey Method are finally determined according to each parameter: change in chosen unit weight, $\mathrm{CA}$ ratio, $\mathrm{FA}_{\mathrm{c}}$ ratio, and $\mathrm{FA}_{\mathrm{f}}$ ratio. An overall net change according to the parameters was then determined to predict the change in VMA according to the changes in gradation. As shown in Table 3.10, some parameters increase the VMA while other decrease the VMA and net change is a reflection of the magnitude of each 
change. The net changes in VMA are then added or subtracted to the VMA of the contractor's mix which was the starting mix design for the Bailey analysis. The changes in VMA added to the VMA of the contractor's mix design give a prediction for the VMA in the coarse and fine mixtures.

Table 3.10 Changes in VMA According to Bailey Parameters and Overall Net Change

\begin{tabular}{|c|c|c|c|c|c|c|c|c|}
\cline { 2 - 9 } \multicolumn{1}{c|}{} & \multicolumn{4}{c|}{ Greer Asphalt } & \multicolumn{4}{c|}{ West Virginia Paving } \\
\cline { 2 - 9 } \multicolumn{1}{c|}{} & \multicolumn{2}{|c|}{ 9.5mm } & \multicolumn{2}{c|}{ 19mm } & \multicolumn{2}{c|}{ 9.5mm } & \multicolumn{2}{c|}{ Wearing I } \\
\hline $\begin{array}{c}\text { Change Due to Following } \\
\text { Parameters }\end{array}$ & Coarse & Fine & Coarse & Fine & Coarse & Fine & Coarse & Fine \\
\hline Percent Chosen Unit Weight & 1.25 & 1.00 & 2.00 & 0.67 & 2.50 & 0.83 & 1.25 & 1.83 \\
\hline CA & -0.75 & -0.11 & -0.10 & -0.34 & -1.50 & 0.00 & -0.65 & 0.34 \\
\hline FA $_{\mathrm{c}}$ & -0.60 & 0.00 & -0.20 & -0.20 & 0.00 & 0.00 & -0.20 & 0.40 \\
\hline FA $_{\mathrm{f}}$ & 0.60 & $\mathrm{NA}$ & -0.40 & 0.80 & 1.20 & $\mathrm{NA}$ & 0.20 & $\mathrm{NA}$ \\
\hline Net Change in VMA & 0.5 & 0.9 & 1.3 & 0.9 & 2.2 & 0.8 & 0.6 & 2.6 \\
\hline
\end{tabular}

\subsubsection{Greer Asphalt 9.5mm Coarse Mixture Example}

The change due to percent chosen unit weight is determined by subtracting the percent passing the Bailey PCS in the coarse gradation from the percent passing the Bailey PCS in the contractors mix, seen in Table 3.2, and dividing by four which is described in Table 2.13 for coarse mixtures.

Percent Chosen Unit Weight $=\frac{P_{\text {Bailey PCS, Contractor }}-P_{\text {Bailey PCS, Coarse }}}{4}=\frac{37-32}{4}=1.25$

The change due to CA is determined by subtracting the CA from the contractor's mixture from the CA of the coarse mixture and dividing by 0.20 which is described in Table 2.13 for coarse mixtures.

$$
C A=\frac{C A_{\text {Coarse }}-C A_{\text {Contractor }}}{0.20}=\frac{0.51-0.66}{0.20}=-0.75
$$

The changes in VMA due to $\mathrm{FA}_{\mathrm{c}}$ and $\mathrm{FA}_{\mathrm{f}}$ are determined by subtracting the Bailey parameter value of the coarse mixture from the parameter value of the contractor's mixture and 
dividing by 0.05 which is described in Table 2.13 for coarse mixtures. Note that the value from the coarse mixture is subtracted from the contractor's mixture to produce proper sign (positive or negative) values indicated in Table 2.12 as the Bailey parameter values of $\mathrm{FA}_{\mathrm{c}}$ and $\mathrm{FA}_{\mathrm{f}}$ increase.

$$
\begin{aligned}
& F A_{c}=\frac{F A_{c, \text { Contractor }}-F A_{c, \text { Coarse }}}{0.05}=\frac{0.38-0.41}{0.05}=-0.60 \\
& F A_{f}=\frac{F A_{f, \text { Contractor }}-F A_{f, \text { Coarse }}}{0.05}=\frac{0.50-0.47}{0.05}=0.60
\end{aligned}
$$

Following the calculation of the four Bailey parameters, a net change in VMA is determined. The net change is determined by adding the values of the four parameters together. The net change is dependent on whether the parameters indicated an increase or a decrease in VMA which can result in a net change near zero if the positive values cancel the negative values.

$$
\begin{aligned}
\text { Net Change In VMA } & =\text { Percent Chosen Unit Weight }+C A+F A_{c}+F A_{f} \\
& =1.25+-0.75+-0.60+0.60=0.50
\end{aligned}
$$

\subsubsection{West Virginia Paving Wearing I Fine Mixture Example}

The change due to percent chosen unit weight is determined by subtracting the percent passing the Bailey PCS in the contractor gradation from the percent passing the Bailey PCS in the fine mix, seen in Table 3.3, and dividing by six which is described in Table 2.13 for fine mixtures.

Percent Chosen Unit Weight $=\frac{P_{\text {Bailey PCS, Fine }}-P_{\text {Bailey PCS, Contractor }}}{6}=\frac{46-35}{6}=1.83$

The change due to CA is determined by subtracting the CA from the contractor's mixture from the CA of the fine mixture and dividing by 0.35 which is described in Table 2.13 for coarse mixtures.

$$
C A=\frac{C A_{\text {Fine }}-C A_{\text {Contractor }}}{0.35}=\frac{0.92-0.80}{0.35}=0.34
$$


The changes in VMA due to $\mathrm{FA}_{\mathrm{c}}$ and $\mathrm{FA}_{\mathrm{f}}$ are determined by subtracting the Bailey parameter value of the fine mixture from the parameter value of the contractor's mixture and dividing by 0.05 which is described in Table 2.13 for coarse mixtures. Note that the value from the coarse mixture is subtracted from the contractor's mixture to produce proper sign (positive or negative) values indicated in Table 2.12 as the Bailey parameter values of $\mathrm{FA}_{\mathrm{c}}$ and $\mathrm{FA}_{\mathrm{f}}$ increases.

$$
\begin{aligned}
& F A_{c}=\frac{F A_{c, \text { Contractor }}-F A_{c, \text { Fine }}}{0.05}=\frac{0.41-0.39}{0.05}=0.40 \\
& F A_{f}=\frac{F A_{f, \text { Contractor }}-F A_{f, \text { Fine }}}{0.05}=\frac{N A-N A}{0.05}=N A
\end{aligned}
$$

Following the calculation of the four Bailey parameters, a net change in VMA is determined. The net change is determined by adding the values of the four parameters together. The net change is dependent on whether the parameters indicated an increase or a decrease in VMA which can result in a net change near zero if the positive values cancel the negative values.

$$
\begin{gathered}
\text { Net Change InVMA }=\text { Percent ChosenUnitWeight }+C A+F A_{c}+F A_{f} \\
=1.83+0.34+0.40+N A=2.6
\end{gathered}
$$




\subsection{Statistical Analysis of Results}

The results from the laboratory testing were compared to the Bailey prediction using the statistical software ANOVA contained within the Microsoft Excel program. Student t statistics were computed to determine if the data was significant enough to reject the hypothesis. The hypothesis was that the slope of the correlation between the Bailey predication and lab results were equal to 1 for VMA. This would indicate that the Bailey predication and WVU lab results were identical.

\subsection{Summary of Research Methodology}

The experimental program was designed to provide an analysis of four mixes that are approved for the construction of flexible pavements in West Virginia. The Bailey parameters of these mixes were analyzed. In addition, modified mixes which represent both coarser and finer aggregate blends and three levels of asphalt content were prepared to determine if the changes in the volumetric properties of these blends correspond to the estimated changes according to the Bailey Method. 


\section{CHAPTER 4: COMPUTER ANALYSIS OF BAILEY METHOD}

The Bailey Method requires a vast amount of extensive equations and iterations to fully utilize the method. Selecting a chosen unit weight to adjust the desired blend of the new gradation requires an iteration process. Therefore, an Excel spreadsheet was created to perform the Bailey analysis. By using the program, quick iterations of the Bailey Method to determine gradation shifts and variations to the aggregate ratios can be performed. The user interface of the Excel spreadsheet is shown in Figure 4.1. The figure displays all required input information to execute the Bailey analysis. The figure also displays a gradation chart with required control points that is automatically configured when all necessary data is entered into the spreadsheet.

The computer spreadsheet was developed using a colored coded system to provide an easier input system for the user. The spreadsheet uses five different color variations to indicate the function of a particular data input field. Table 4.1 displays the color designations and the appropriate input for each field.

The Bailey Method is an appropriate method for analyzing aggregate blends for any method of mix design. The program was developed for Marshall, SuperPave and SMA mixes. A drop down menu is used to select the mix design method. Once the mix design method is chosen, the mix type can be selected. Examples for each would be SuperPave $-9.5 \mathrm{~mm}$ or Marshall - Wearing I. The mix design method and mix type are shown in the spreadsheet as a yellow field indicating that it requires input. Following the selection of mix design method and mix type in the two yellow fields, the blue fields for nominal maximum aggregate size and primary control sieve will be automatically generated. 


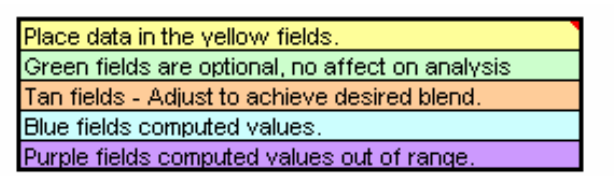

Purple fields computed values out of range.
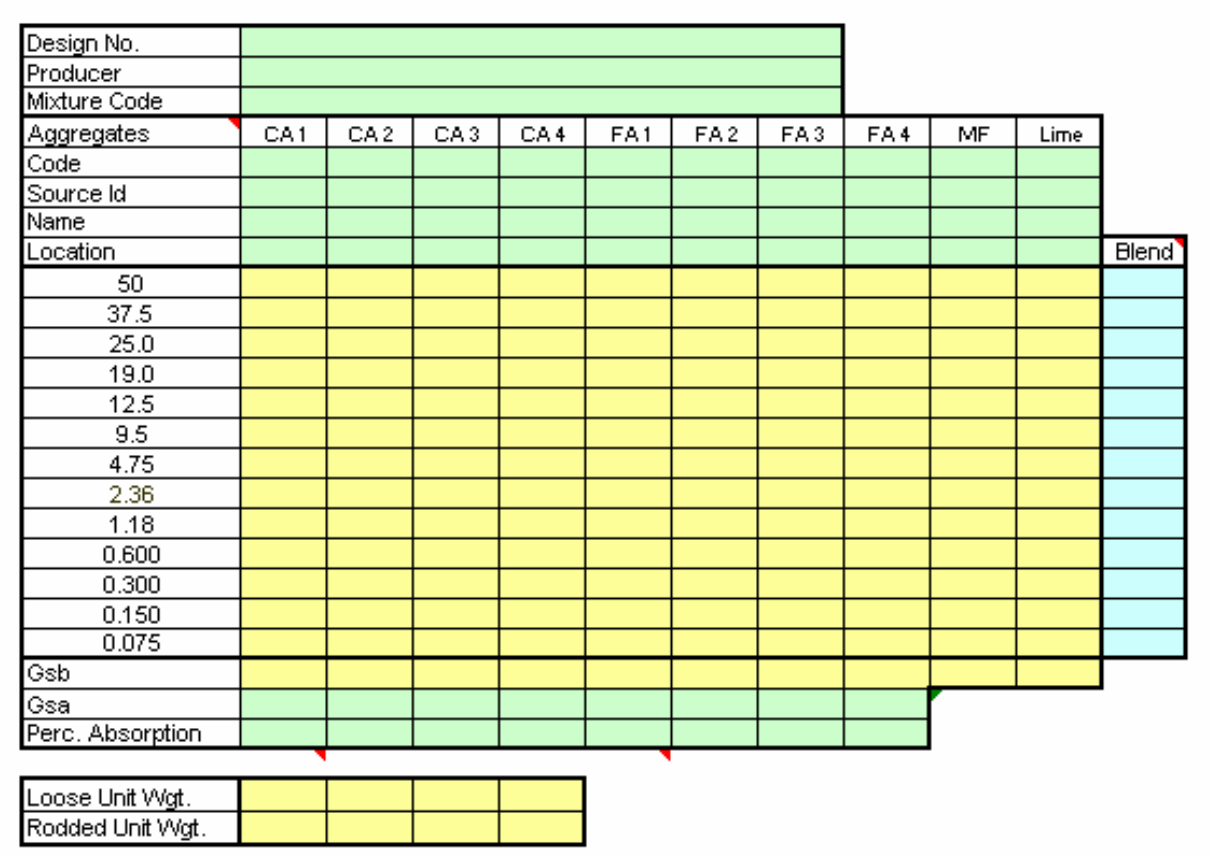

Percent passing the $0.075 \mathrm{~mm}$ sieve desired in the Combined Elend $\square$

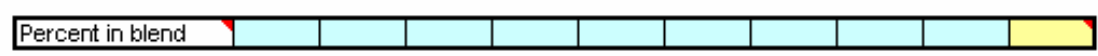

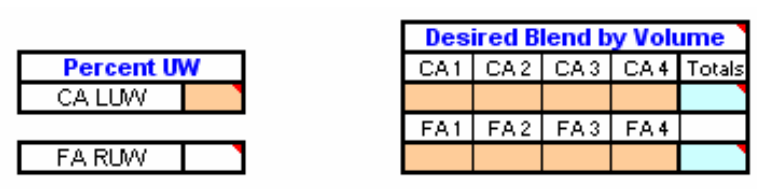

Bailey class Fine Mix

No guidelines
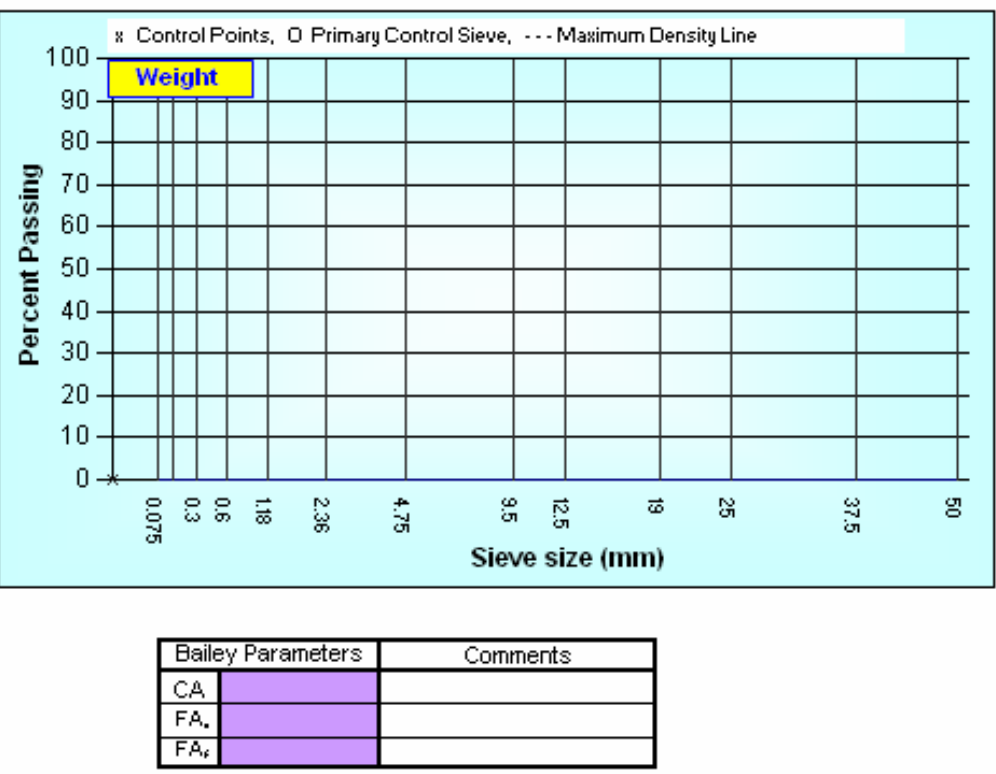

Figure 4.1 Excel Spreadsheet User Interface 


\section{Table 4.1 Color Designations for Data Input}

\begin{tabular}{|l|}
\hline Yellow Fields - requires data input \\
\hline Green Fields - optional, no affect on analysis \\
\hline Tan Fields - adjust to achieve desired blend. \\
\hline Blue Fields - computed values. \\
\hline Purple Fields - computed values out of range. \\
\hline
\end{tabular}

\section{Table 4.2 Mix Design Input}

\begin{tabular}{|c|c|}
\hline Mix design method & \\
\hline Mix type & \\
\hline Nominal Maximum Aggregate Size & \\
\hline Primary Control Sieve & \\
\hline
\end{tabular}

Table 4.2 shows the fields for mix design method, mix type, nominal maximum aggregate size, and primary control sieve and the appropriate color coordination.

Once the mix design method and type are chosen, the aggregate information for appropriate stockpiles must be inputted. The gradation of each aggregate source must be inputted into the appropriate coarse and fine aggregate column in the yellow fields. Each aggregate has optional field inputs shown in green that refer to the aggregates code, source ID, name, and location to classify the origin of each aggregate.

The remaining yellow fields that require information about the aggregate are the bulk specific gravity and loose or rodded unit weight. The loose unit weight is required for the coarse aggregate and the rodded unit weight is required for the fine aggregate although both can be entered for additional information. The information for maximum theoretical specific gravity and percent water absorption is shown in green fields as information that is optional and will not affect the analysis results. 
The remaining blue fields are the computed values for the aggregate blend gradation and the percentage of each aggregate in the mix design which will be adjusted according to chosen unit weight. The column for the final aggregate blend is shown in blue, unless the blended gradation does not fall within the mix design control points for SuperPave or Marshall. In this case, the fields will turn purple to indicate that the values are out of range and require an adjustment to the blend percents. Table 4.3 shows the Excel spreadsheet interface for the aggregate information input section.

Table 4.3 Aggregate and Gradation Information

\begin{tabular}{|c|c|c|c|c|c|c|c|c|c|c|c|}
\hline Design No. & & & & & & & & & & & \\
\hline Producer & & & & & & & & & & & \\
\hline Mixture Code & & & & & & & & & & & \\
\hline Aggregates & CA 1 & CA 2 & CA 3 & CA 4 & FA 1 & FA 2 & FA 3 & FA 4 & MF & Lime & \\
\hline Code & & & & & & & & & & & \\
\hline Source Id & & & & & & & & & & & \\
\hline Name & & & & & & & & & & & \\
\hline Location & & & & & & & & & & & Blend \\
\hline 50 & & & & & & & & & & & \\
\hline 37.5 & & & & & & & & & & & \\
\hline 25.0 & & & & & & & & & & & \\
\hline 19.0 & & & & & & & & & & & \\
\hline 12.5 & & & & & & & & & & & \\
\hline 9.5 & & & & & & & & & & & \\
\hline 4.75 & & & & & & & & & & & \\
\hline 2.36 & & & & & & & & & & & \\
\hline 1.18 & & & & & & & & & & & \\
\hline 0.600 & & & & & & & & & & & \\
\hline 0.300 & & & & & & & & & & & \\
\hline 0.150 & & & & & & & & & & & \\
\hline 0.075 & & & & & & & & & & & \\
\hline Gsb & & & & & & & & & & & \\
\hline Gsa & & & & & & & & & & & \\
\hline$\%$ Absorption & & & & & & & & & & & \\
\hline Percent in blend & & & & & & & & & & & \\
\hline Loose Unit Weight & & & & & & & & & & & \\
\hline Rodded Unit Weight & & & & & & & & & & & \\
\hline
\end{tabular}


The remaining user input to compute the Bailey analysis is the chosen unit weight and the desired blend volumes for each aggregate source as shown in Table 4.4. This section, identified with tan fields, is used for the iteration process of the Bailey Method to evaluate a blend. Adjusting the chosen unit weight, either in the coarse or fine direction, will recalculate the gradation and change the percentages of each aggregate source in the blend. The desired blend by volume can also be adjusted to create an optimal blend by altering the final percentage of each aggregate to be used in the blend. The desired blend by volume for both the coarse and fine aggregate is selected and it must total $100 \%$ which is automatically calculated in the blue field shown in the final column. The blue field for total will turn purple if the total does not equal the required $100 \%$ by volume for each aggregate classification - coarse and fine.

\section{Table 4.4 Chosen Unit Weight and Desired Blend Volumes}

\begin{tabular}{|l|l|}
\hline Chosen Unit Weight & \\
\hline
\end{tabular}

\begin{tabular}{|c|c|c|c|c|}
\hline \multicolumn{5}{|c|}{ Desired Blend by Volume } \\
\hline CA 1 & CA 2 & CA 3 & CA 4 & Totals \\
\hline & & & & \\
\hline FA 1 & FA 2 & FA 3 & FA 4 & \\
\hline & & & & \\
\hline
\end{tabular}

When all required and desired input fields are entered into the spreadsheet, the program computes the Bailey aggregate ratio values. Table 4.5 shows the aggregate ratio and comments portion of the spreadsheet. The values are computed and then compared to recommended values according to Bailey. If the aggregate ratios do not fall within the recommended values, the field will turn purple and a statement of potential problems is displayed in the comments section.

\section{Table 4.5 Aggregate Ratios}

\begin{tabular}{|c|l|l|}
\hline \multicolumn{2}{|c|}{ Aggregate Ratios } & Comments \\
\hline $\mathrm{CA}$ & & \\
\hline $\mathrm{FA}_{\mathrm{c}}$ & & \\
\hline $\mathrm{FA}_{\mathrm{f}}$ & & \\
\hline
\end{tabular}


The computer program was tested using a Bailey analysis example provided by the Transportation Research Board as a trial procedure to test the results from the computer program (Vavrik, et. al., 2002). This was conducted to check for computer equation errors, in addition to hand calculations, to avoid improperly calculating the inputted information. The analysis from the test showed identical results to the results from the Transportation Research Board and verified the Bailey calculations developed for this research. 


\section{CHAPTER 5: RESULTS AND ANALYSIS}

\subsection{BAILEY RESULTS}

The prediction results according to Bailey and the WVU lab results are depicted in Tables 5.1 and 5.2. The tables display the results for three mix blends (contractor, coarse, fine) with ranging asphalt binder contents (target, high, low) for each original contractor mix gradation. The net difference between the WVU lab results and the Bailey prediction are depicted in the tables.

The coarse gradations for the Greer $19 \mathrm{~mm}$ and West Virginia Paving Wearing I were the most accurate estimations for the Bailey coarse graded mixtures with a range of 0.2 to 1.1 of difference between the actual lab results and the estimated value. The fine gradations for the Greer $9.5 \mathrm{~mm}$ and West Virginia Paving $9.5 \mathrm{~mm}$ were the most accurate estimations for the Bailey fine graded mixtures, with the exception of the high asphalt content for the Greer $9.5 \mathrm{~mm}$ sample, with a range of 0 to 0.7 of difference between the actual lab results and the estimated value. The perfect prediction of zero difference occurred twice for the two fine graded mixtures previously mentioned.

The most irregular results where the predictions of the fine gradation for the West Virginia Paving Wearing I mixture. The difference in the actual lab results from the Bailey prediction ranged from 3.8 to 4.6 .

The correlation graph of the entire sample set, Figure 5.1, shows the WVU lab results versus the Bailey predictions with a linear regression line. Figure 5.1 displays the correlation results and the linear regression line in the form of $y=a x+b$, where " $a$ " is the slope and " $b$ " is the point the line intersects the y-axis. The Excel linear regression function was used to fit a line to the data. This function also computes an analysis of variance, ANOVA. The results of this 
analysis are presented in Appendix B. The results for the entire data set are shown in Table B.1. The regression coefficients are 0.702 and 5.27 for $a$ and $b$ with standard errors of 0.211 and 3.563, respectively. An ideal result would yield a line with a slope of 1 that intersects the y-axis at 0 . To determine if the slope coefficient is significantly different from 1 , a Student $t$ statistic is computed as:

$t_{\text {stat }}=\frac{\left(a_{\text {reg }}-a_{\text {ideal }}\right)}{S_{e}}=\frac{(0.702-1.000)}{0.211}=-1.412$

The $t_{\text {crit }}$ for $95 \%$ confidence and 22 degrees of freedom is \pm 2.074 . Since the $t_{\text {stat }}$ is within the range of $t_{\text {crit }}$ there is insufficient evidence to reject the hypothesis that the slope coefficient, a, is equal to 1. This is an indication that the Bailey computed and laboratory results are similar.

As shown in Figure 5.1, the Wearing I fine blends appear to be outliers. The laboratory determined VMA values are in the range of 14.8 to 16.0 , which are reasonable values. The corresponding VMA values computed with the Bailey Method are in the range of 19.0 to 19.8, which is much higher than could be reasonably expected. Based on this observation, the results for the Marshall Wearing I mixes were omitted from Figure 5.2. New a and $b$ values for the SuperPave mixtures were computed. The resulting coefficients were 0.971 and 0.119 , with standard errors of 0.161 and 2.757 , for $a$ and $b$, respectively. Repeating the calculation of $t_{\text {stat }}$ as shown in Equation 5.1 resulted in a $t_{\text {stat }}$ of -0.180 and $t_{\text {crit, }}$ with 16 degrees of freedom, is \pm 2.120 . Hence, there is insufficient evidence to reject the hypothesis that the slope, a, is equal to 1 . This is an indication that the Bailey computed and laboratory results are similar. The difference between $t_{\text {stat }}$ and $t_{\text {crit }}$ for the SuperPave mixtures, which omitted the Marshall samples, was 1.940 and the difference for the entire sample set was 0.662. This indicates that the SuperPave mixtures display a much higher correlation between the Bailey predication and VMA lab results. 
As seen in Figure 5.1 and 5.2, the correlation coefficient, $\mathrm{R}^{2}$, value doubled from 0.34 to 0.69 with the omission of the Marshall Wearing I mixture.

Table 5.1 Greer Asphalt VMA Analysis

\begin{tabular}{|c|c|c|c|c|c|c|c|c|c|}
\cline { 2 - 10 } \multicolumn{1}{c|}{} & \multicolumn{9}{c|}{ 9.5mm Mixture } \\
\hline Gradation & \multicolumn{3}{|c|}{ Contractor } & \multicolumn{3}{c|}{ Coarse } & \multicolumn{3}{c|}{ Fine } \\
\hline Percent Binder & Low & Target & High & Low & Target & High & Low & Target & High \\
\hline WVU Lab & 18.4 & 16.7 & 16.2 & 17.4 & 17.6 & 19.2 & 19.3 & 18.3 & 20.0 \\
\hline Bailey & - & - & - & 18.9 & 17.2 & 16.7 & 19.3 & 17.6 & 17.1 \\
\hline Net Difference & - & - & - & -1.5 & 0.4 & 2.5 & 0 & 0.7 & 2.9 \\
\hline
\end{tabular}

\begin{tabular}{|c|c|c|c|c|c|c|c|c|c|}
\cline { 2 - 11 } \multicolumn{1}{c|}{} & \multicolumn{9}{c|}{ 19mm Mixture } \\
\hline Gradation & \multicolumn{3}{c|}{ Contractor } & \multicolumn{3}{c|}{ Coarse } & \multicolumn{3}{c|}{ Fine } \\
\hline Percent Binder & Low & Target & High & Low & Target & High & Low & Target & High \\
\hline WVU Lab & 12.6 & 12.3 & 12.8 & 14.2 & 13.4 & 14.9 & 14.4 & 15.0 & 15.0 \\
\hline Bailey & - & - & - & 13.9 & 13.6 & 14.1 & 13.5 & 13.2 & 13.7 \\
\hline Net Difference & - & - & - & 0.3 & -0.2 & 0.8 & 0.9 & 1.8 & 1.3 \\
\hline
\end{tabular}

Table 5.2 West Virginia Paving VMA Analysis

\begin{tabular}{|c|c|c|c|c|c|c|c|c|c|}
\cline { 2 - 11 } \multicolumn{1}{c|}{} & \multicolumn{9}{c|}{$9.5 m m$ Mixture } \\
\hline Gradation & \multicolumn{3}{c|}{ Contractor } & \multicolumn{3}{c|}{ Coarse } & \multicolumn{3}{c|}{ Fine } \\
\hline Percent Binder & Low & Target & High & Low & Target & High & Low & Target & High \\
\hline WVU Lab & 17.3 & 17.0 & 16.6 & 17.6 & 18.1 & 17.8 & 18.1 & 18.1 & 17.9 \\
\hline Bailey & - & - & - & 19.5 & 19.2 & 18.8 & 18.1 & 17.8 & 17.4 \\
\hline Net Difference & - & - & - & -1.9 & -1.1 & -1.0 & 0 & 0.3 & 0.5 \\
\hline
\end{tabular}

\begin{tabular}{|c|c|c|c|c|c|c|c|c|c|}
\cline { 2 - 11 } \multicolumn{1}{c|}{} & \multicolumn{9}{c|}{ Wearing I Mixture } \\
\cline { 2 - 11 } \multicolumn{1}{c|}{ Gradation } & \multicolumn{3}{c|}{ Contractor } & \multicolumn{3}{c|}{ Coarse } & \multicolumn{3}{c|}{ Fine } \\
\cline { 2 - 11 } Percent Binder & Low & Target & High & Low & Target & High & Low & Target & High \\
\hline WVU Lab & 16.4 & 17.1 & 16.9 & 17.7 & 16.6 & 17.2 & 15.2 & 15.9 & 14.9 \\
\hline Bailey & - & - & - & 17.0 & 17.7 & 17.5 & 19.0 & 19.7 & 19.5 \\
\hline Net Difference & - & - & - & 0.7 & -1.1 & -0.3 & -3.8 & -3.8 & -4.6 \\
\hline
\end{tabular}




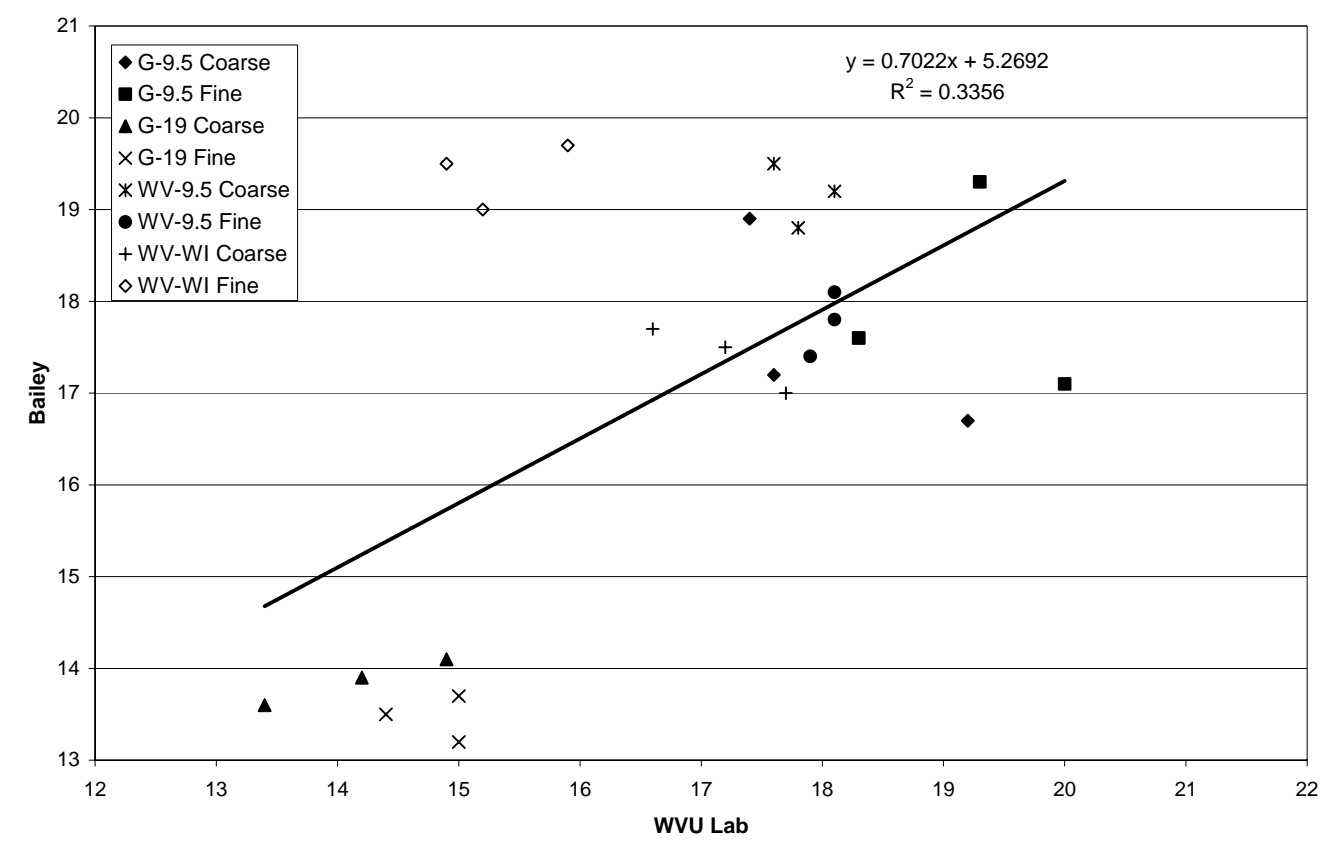

Figure 5.1 VMA Correlations - WVU Lab and Bailey Prediction for All Samples

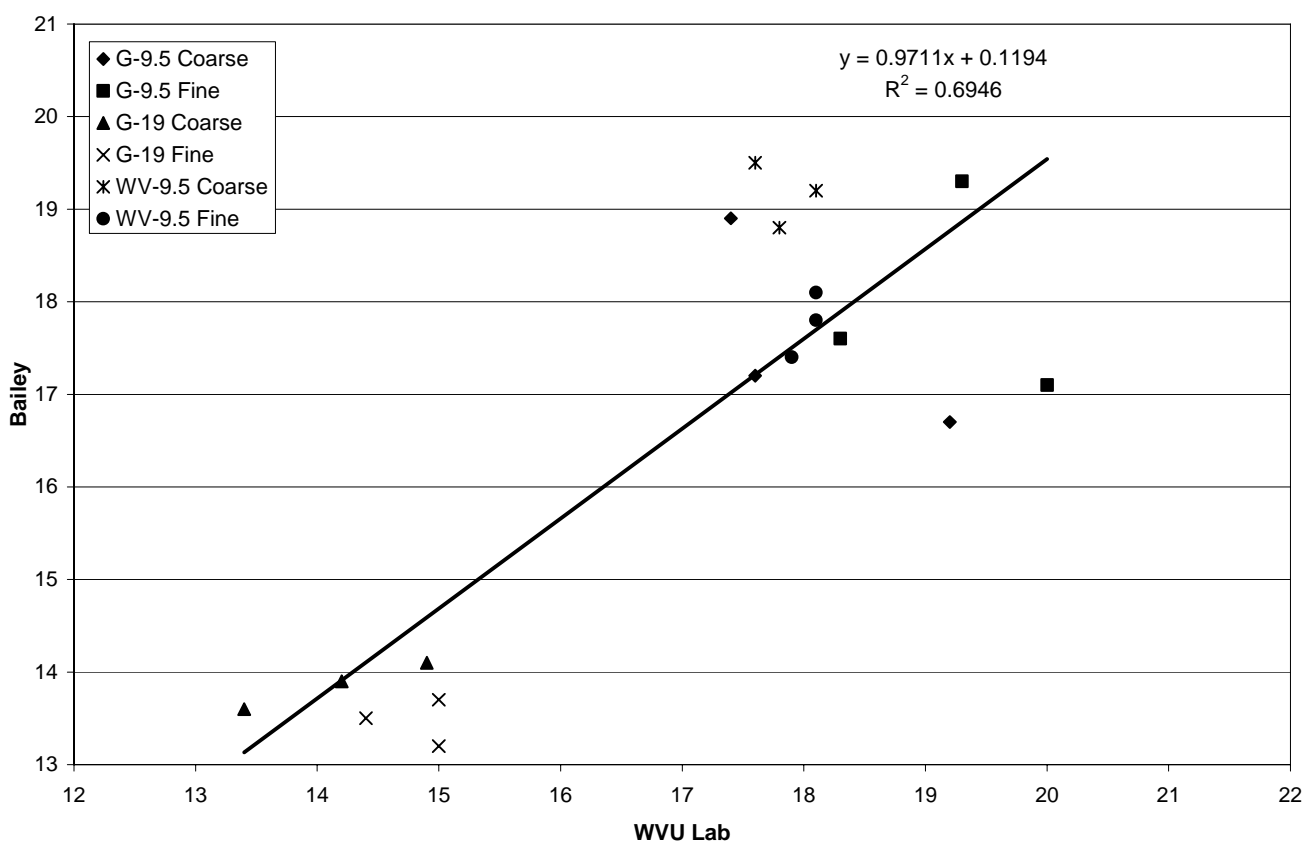

Figure 5.2 VMA Correlations - WVU Lab and Bailey Prediction for SuperPave Mixtures 


\subsection{ANALYSIS FOR 9.5MM AGGREGATE MIXTURES}

The determination between a coarse mixture and a fine mixture is based on the chosen unit weight. According to the Bailey Method, a chosen unit weight of 90 percent is the separation point. This is also the point at which the VMA should be at the minimum. Figures 5.3, 5.4, and 5.5 display the trend in VMA for the $9.5 \mathrm{~mm}$ aggregate mixtures for low, target, and high asphalt contents, respectively. The lines on the figures were fitted to the data using the second order polynomial trend line function in Excel. One line is for the predicted changes in VMA according to the Bailey Method. The other line was fitted to the VMA determined in the laboratory. The line for the Bailey Method has the characteristic shape shown on Figure 2.5. There is a slight difference in the location of the minimum VMA; Figure 2.5 shows the minimum should be at 90 percent chosen unit weight while the analysis of the $9.5 \mathrm{~mm}$ mixes has the minimum ranging from 82 to 87 percent. The trend line fitted to the laboratory data does not correspond to the shape described by the Bailey Method. In fact, on all three figures the line fitted to the lab data shows a maximum VMA value which corresponds approximately to the location of the Bailey minimum point. 


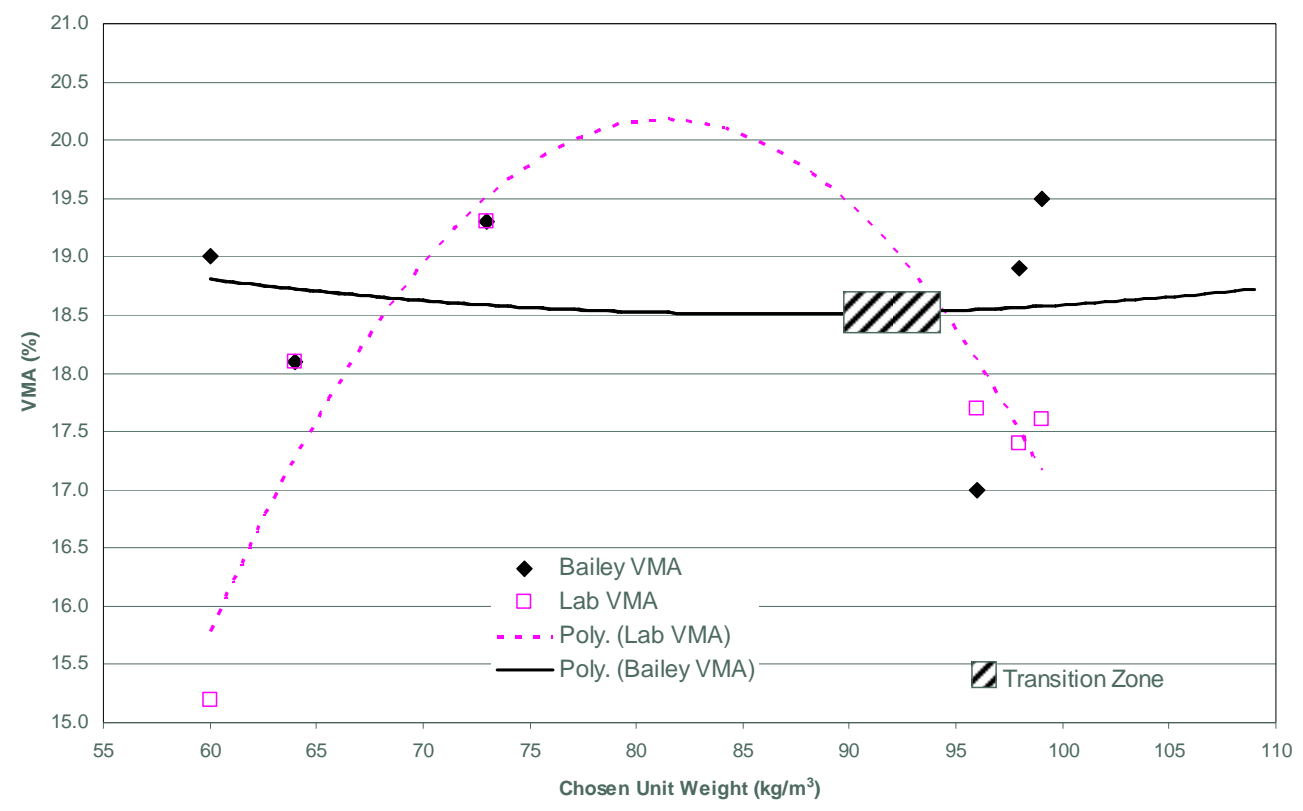

Figure 5.3 VMA vs. Chosen Unit Weight for 9.5mm Aggregate Mixtures at Low Asphalt Content

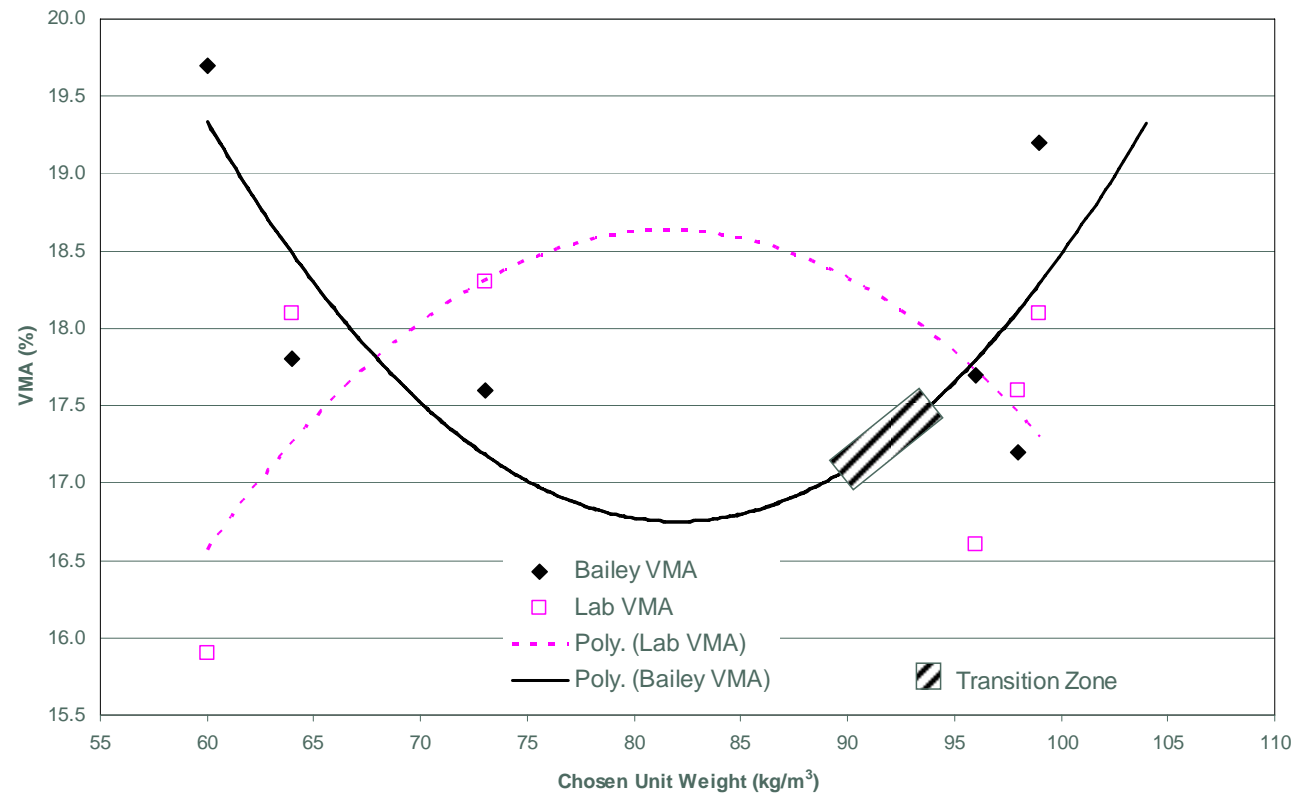

Figure 5.4 VMA vs. Chosen Unit Weight for 9.5mm Aggregate Mixtures at Target Asphalt Content 


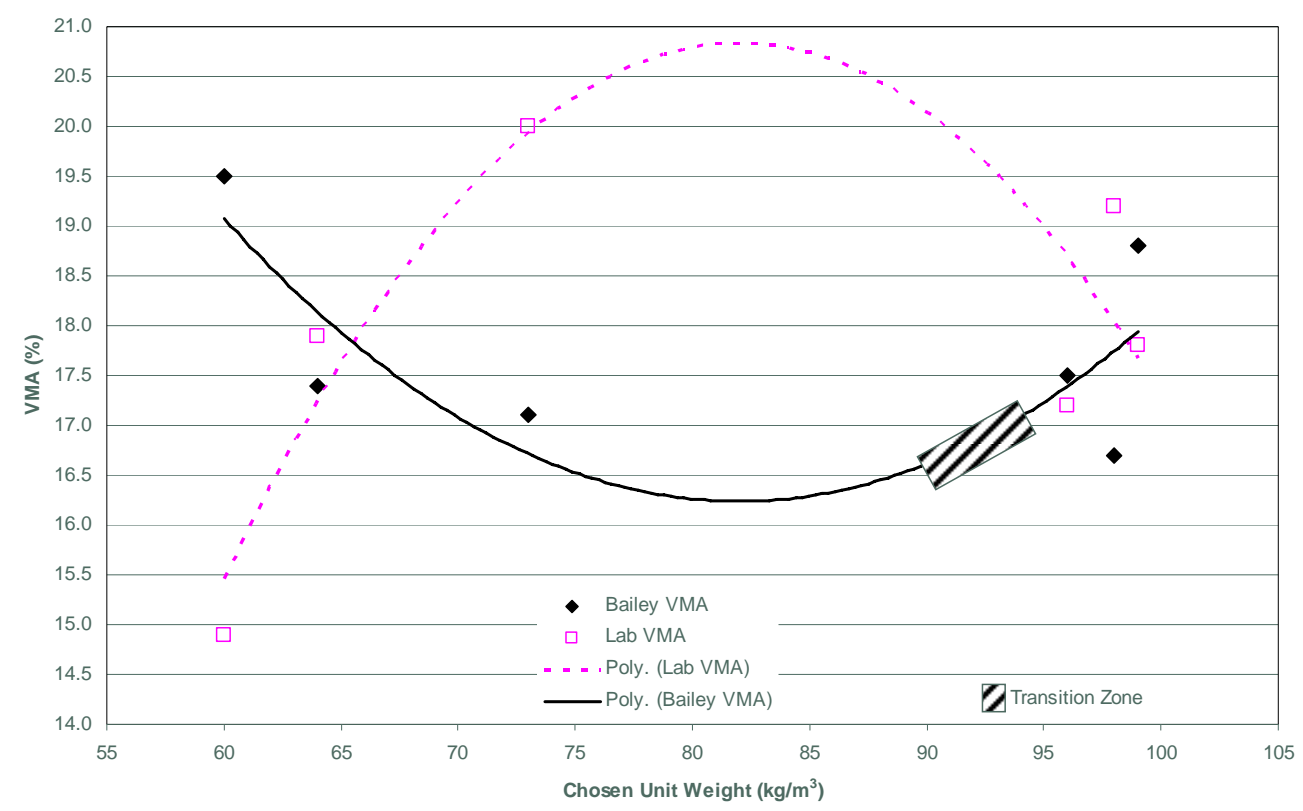

Figure 5.5 VMA vs. Chosen Unit Weight for 9.5mm Aggregate Mixtures at High Asphalt Content

\subsection{ANALYSIS FOR 19MM AGGREGATE MIXTURES}

The results for the $19 \mathrm{~mm}$ mixture are displayed in Figure 5.6. Since only one $19 \mathrm{~mm}$ mixture was analyzed, Figure 5.6 displays the results for the fine, contractor, and coarse mixtures at the three asphalt contents. The Bailey Method uses measured laboratory results as the baseline for computing how VMA changes in response to changes to the blend of aggregates. In this case, the contractors' mix design served as the baseline and predictions were made of how changing to the coarse and fine blends affect VMA. Hence, only two sets of data are available for establishing a trend line, which would result in a linear relationship so no trend line was placed on Figure 5.6 for the Bailey Method. The polynomial trend line fitted to the laboratory results has the characteristic shape as depicted on Figure 2.5. 
The results for the $19 \mathrm{~mm}$ mixture yielded a minimal VMA content at a chosen unit weight of 94 percent. The results were consistent with the expected change of VMA as the mixture got finer and coarser according to the chosen unit weight.

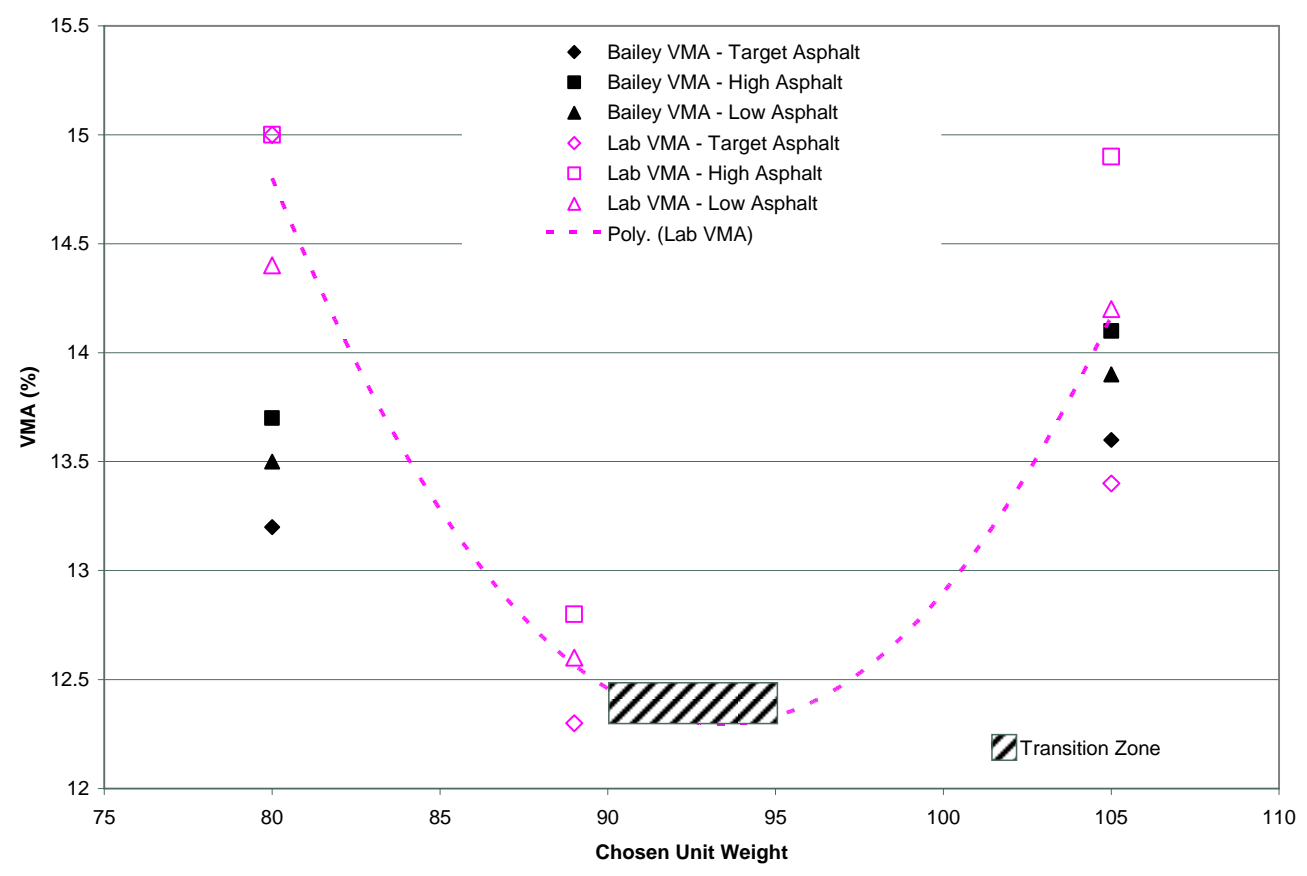

Figure 5.6 VMA vs. Chosen Unit Weight for 19mm Aggregate Mixtures 


\section{CHAPTER 6: CONCLUSIONS AND RECOMMENDATIONS}

\subsection{CONCLUSIONS}

The results from the prediction of VMA through the Bailey Method provided a general trend and estimation to lab results for the various mixtures with an exception to the West Virginia Paving Wearing I Fine Mix which yielded irregular results. The correlation graphs and statistical results show the correlation between the predicted Bailey results and the laboratory tested VMA significantly increased with the omission of the Marshall Wearing I mixture as compared to the SuperPave results. The main difference between the SuperPave and Marshall mix designs is the SuperPave uses crushed limestone for both the coarse and fine aggregate while Marshall mix is a blend of crushed gravel, crushed limestone fine material and natural sand.

The West Virginia Paving Marshall Wearing I fine mixture yielded the most irregular prediction for VMA compared to the laboratory results. The results were 3.8 to 4.6 off the Bailey predicted value. The crushed gravel used in the Marshall mix was round in shape and smooth in texture, although it does meet the WVDOT requirement of a minimum of 80 percent of the material having two fractured faces. The shape and texture characteristics of the gravel is vastly different from the crushed limestone which is highly angular with 100 percent having two or more fractured faces and rough in texture. Figure 6.1 shows typical coarse aggregates used in the Marshall and Superpave $9.5 \mathrm{~mm}$ mixes. In addition, the Marshall mix has 30 percent natural sand which also has a smooth and rounded texture when compared to the crushed limestone fine aggregate used in the SuperPave mixes. The Bailey Method does not directly account for the shape and texture of the aggregate source, but does approximate the aggregate's shape from the 


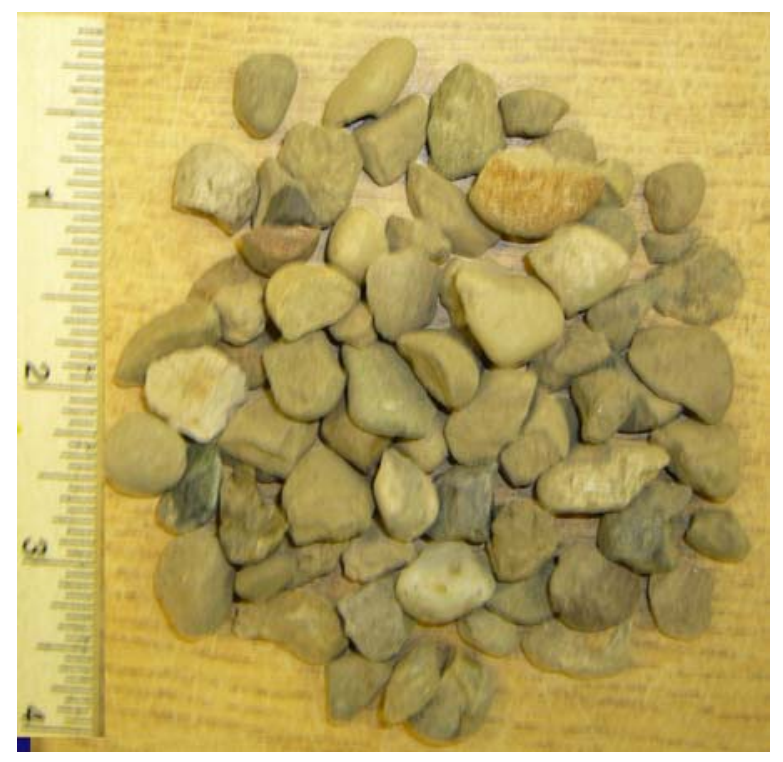

(a) Crushed gravel

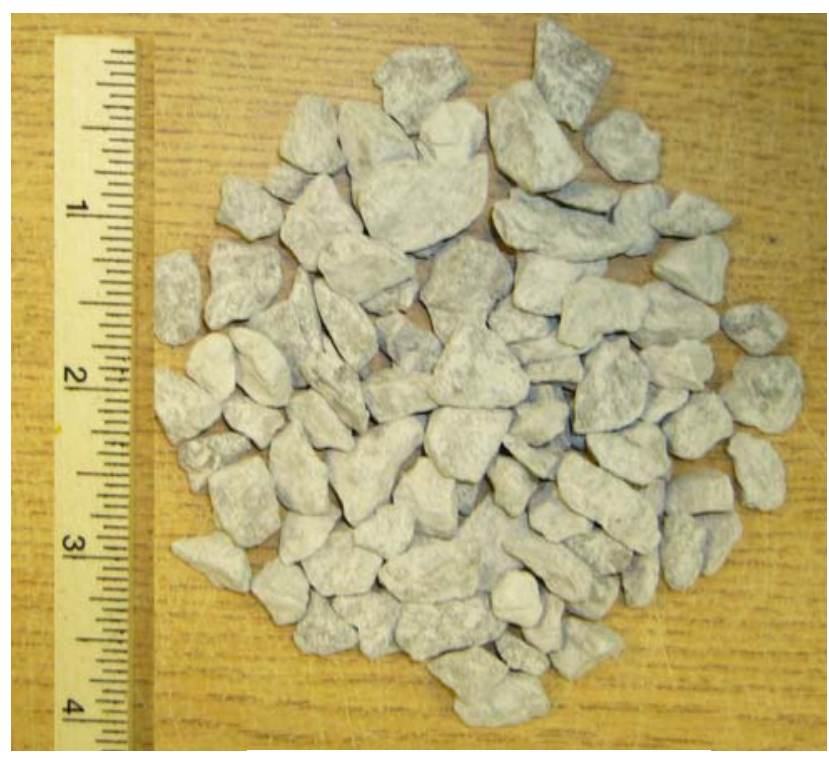

(b) Crushed limestone

Figure 6.1 Coarse aggregates used in Marshall and SuperPave $9.5 \mathrm{~mm}$ mixes

loose and rodded unit weights. The predicted change in VMA according to Bailey could be significantly changed due to the change in aggregate characteristics. It is also possible that the difference in the compaction methods between Marshall and SuperPave affected the results of the comparison.

The Bailey Method predicted an increase in VMA for all the mixtures analyzed in this research compared to the contractors' mixtures as seen in Table 3.10. The only mixture to have a significant decrease in the VMA as compared to the predicted increase according to Bailey was the Marshall Wearing I fine mixture. The Marshall Wearing I mix is the only mixture that contained crushed gravel and sand. Therefore, the fine mixture for the Wearing I contained the highest amount of sand in any mixture which yielded the largest decrease in VMA compared to the predicted increase according to Bailey.

The SuperPave mixtures, consisting of crushed limestone aggregate, yielded a much higher correlation in the prediction of VMA by the Bailey Method compared to laboratory 
results. The correlation value doubled when comparing SuperPave mixtures alone from comparing the entire sample population of SuperPave and Marshall mix designs.

The selection of coarse and fine aggregate designation through the Bailey analysis was also consistent with anticipated trends. Figures 5.3, 5.4, 5.5, and 5.6 indicate the change in VMA as the chosen unit weight changes the mixture from a coarse to fine mixture. The minimum values for VMA anticipated at the change of the mixture from coarse to fine according to Bailey were within 5 to 10 percent for the $9.5 \mathrm{~mm}$ aggregate mixtures. However, the lab values for VMA did not follow the expected trend. The $19 \mathrm{~mm}$ mixture was within 4 percent for the laboratory data. The variation in these minimum values may be attributed to the Bailey Method, the procedure does not address how VMA changes when there is a sufficient change in the gradation to result in reclassifying the mix from coarse to fine and vice versa. The approach in this research was to treat the ratios for the coarse mixture according to coarse characteristics, although each original contractor mix was considered fine by the Bailey Method.

\subsection{RECOMMENDATIONS}

The Bailey Method may be a useful tool to contractors trying to adjust gradations to meet specifications during the mix design process. This method provides a prediction value for the VMA parameter as the mixture chances gradations. The prediction can be used in place of random testing of different mixtures to reach an optimum mix design. This research analysis shows the Bailey Method can provide this useful approach to designing an optimal mix design by providing a adequate prediction to the VMA parameter and testing its verification when used with aggregates meeting the SuperPave requirements. However, the evaluation of the Marshall mix was not as successful. 
Recommendations for future testing would include changes to initial conditions of the mixtures tested. In this research report, all of the original contractors' mix designs, which were used as a beginning point for the Bailey prediction, were fine mixtures according to Bailey. The Bailey Method does not specifically indicate the proper procedure for predicting VMA when the mixture crosses the transition zone of a chosen unit weight between $90-95$ percent. The approach in this analysis was to treat the change from coarse to fine or fine to coarse the same as a fine mix becoming finer or a coarse mix becoming coarser. Future testing would be appropriate to analyze contractor's mixtures that are considered initially as coarse by the Bailey Method and determining if there are significant effects to the prediction of VMA when crossing the transition zone compared to staying above or below limit.

Other recommended testing would involve comparison of different aggregate sources used in the mixtures. Aggregate texture and shape are not evaluated by the Bailey Method. Switching from a crushed limestone with many fractured faces and rough texture to river gravel that is smooth and round could drastically affect the changes in VMA which is not accounted for in the Bailey Method. The Wearing I mixtures that contain sand could also have a significant effect on the prediction by the Bailey method which was seen in the fine mixture for the Wearing I which had the largest decrease in VMA compared to the predicted increase according to Bailey. The effect of sand on the Bailey method prediction could also be analyzed in the future.

The Excel spreadsheet calculator that was developed for this research could be used on other mixes to evaluate characteristics of the mixture such as rutting and compaction problems. The Bailey Method indicates potential construction problems when the aggregate ratios are considered out of range according to the Bailey criteria. The magnitude of these problems could be evaluated as the aggregate ratios change from mixture to mixture. 
Other considerations for future testing could be for SMA mixtures which were not evaluated because the WVDOH does not use SMA designs. The Excel spreadsheet calculator is capable of running the Bailey analysis for SMA mixtures. Testing could also be done with other binder and asphalt content levels. 


\section{REFERENCES}

Aurilio, V., Pine, W.J., and Lum, P., The Bailey Method. Achieving Volumetrics and HMA Compactability. 2005.

Kandhal, P.S., Foo, K.Y., and Mallick, R.B., A Critical Review of VMA Requirements in SuperPave. NCAT Report No. 98-1. Auburn University, AL, January 1998.

Marathon Ashland. Material Safety Data Sheet. Marathon Performance Graded Asphalt Binder. ID NO. 0142MAR019. 2006.

Microsoft Excel, Microsoft Corp., Redmond, WA, 2003

Pine, W.J., "The Bailey Method”, Workshop Power Point Presentation, The Heritage Research Group, Indianapolis, Indiana. Created 2005.

Roberts, F.L., Kandhal, P.S., and Brown, R., Hot Mix Asphalt Materials, Mixture Design, and Construction. National Center for Asphalt Technology. Second Edition. 1996.

Vavrik, W.R., Bailey, R., and Pine, W.J., Bailey Method for Gradation Selection in Hot-Mix Asphalt Mixture Design. Transportation Research Circular. Transportation Research Board of The National Academies. October 2002

Zaniewski, J.P., and Reyes, C., Evaluation of the Effects of Fines on Asphalt. West Virginia Division of Highways. Charleston, WV, June 2003.

\section{SPECIFICATIONS AND TEST METHODS}

Specific Gravity and Absorption of Coarse Aggregate, AASHTO T85, 2002.

Specific Gravity and Absorption of Fine Aggregate, AASHTO T84, 2002.

Bulk Specific Gravity of Compacted Bituminous Mixtures using Saturated Surface Dry Specimens, AASHTO T166, 2002.

Theoretical Maximum Specific Gravity and Density of Bituminous Mixtures, AASHTO T209, 2002.

Method for Preparing and Determining the Density of HMA Specimens by Means of the SuperPave Gyratory Compactor, AASHTO TP4, 2002.

Method for Determining the Unit Weight and Voids in Aggregate, AASHTO T-19, 2002.

Resistance to Plastic Flow of Bituminous Mixtures using the Marshall Apparatus. AASHTO T243, 2002. 
SuperPave Volumetric Mix Design. AASHTO MP2-03, 2002.

West Virginia Department of Transportation. Material Procedure 401.02.22. Guide to Designing Hot-Mix Asphalt using the Marshall Design Method. March 2000.

West Virginia Department of Transportation. Material Procedure 401.02.29. Guideline for Quality Control and Acceptance Requirements for SuperPave Hot-Mix Asphalt. March 2000. 


\section{APPENDIX A - VOLUMETRIC RESULTS}

\section{Table A1 Greer 9.5mm Contractor Blend Volumetric Results}

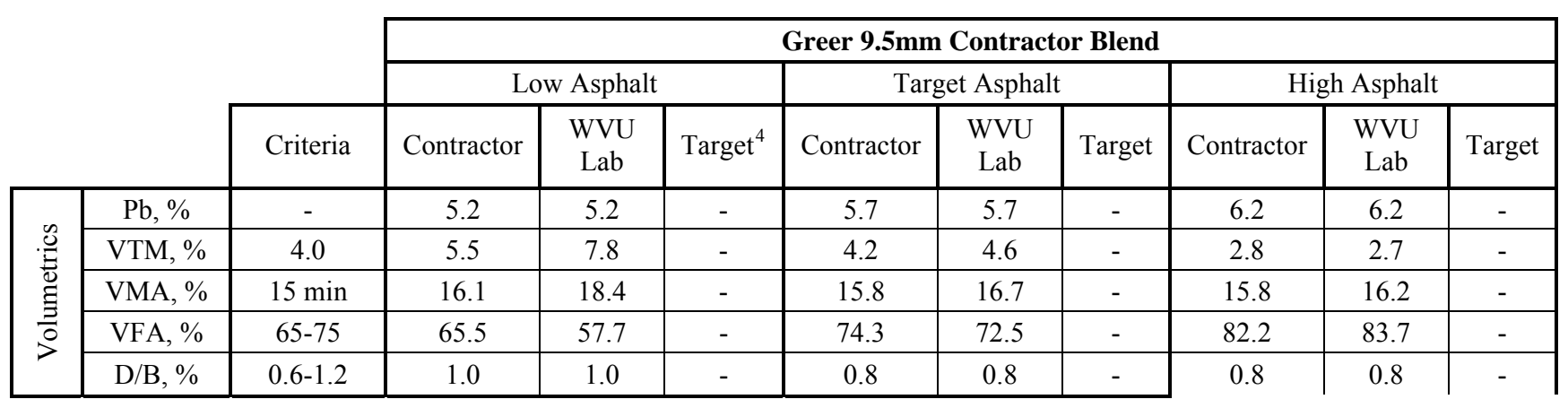

\section{Table A2 Greer 9.5mm Coarse Blend Volumetric Results}

\begin{tabular}{|c|c|c|c|c|c|c|c|c|c|c|c|}
\hline & & & \multicolumn{9}{|c|}{ Greer 9.5mm Coarse Blend } \\
\hline & & & \multicolumn{3}{|c|}{ Low Asphalt } & \multicolumn{3}{|c|}{ Target Asphalt } & \multicolumn{3}{|c|}{ High Asphalt } \\
\hline & & Criteria & Contractor & $\begin{array}{c}\text { WVU } \\
\text { Lab }\end{array}$ & Target & Contractor & $\begin{array}{c}\text { WVU } \\
\text { Lab }\end{array}$ & Target & Contractor & $\begin{array}{c}\text { WVU } \\
\text { Lab }\end{array}$ & Target \\
\hline \multirow{5}{*}{ 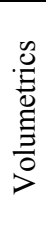 } & $\mathrm{Pb}, \%$ & - & - & 4.7 & - & - & 5.2 & - & - & 5.7 & - \\
\hline & VTM, $\%$ & 4.0 & - & 7.5 & - & - & 6.8 & - & - & 7.6 & - \\
\hline & VMA, \% & $15 \mathrm{~min}$ & - & 17.4 & 18.9 & - & 17.6 & 17.2 & - & 19.2 & 16.7 \\
\hline & VFA, \% & $65-75$ & - & 56.8 & - & - & 61.3 & - & - & 60.9 & - \\
\hline & $\mathrm{D} / \mathrm{B}, \%$ & $0.6-1.2$ & - & 1.0 & - & - & 0.8 & - & - & 0.8 & - \\
\hline
\end{tabular}

\section{Table A3 Greer 9.5mm Fine Blend Volumetric Results}

\begin{tabular}{|c|c|c|c|c|c|c|c|c|c|c|c|}
\hline & & & \multicolumn{9}{|c|}{ Greer 9.5mm Fine Blend } \\
\hline & & Criteria & Contractor & $\begin{array}{l}\text { WVU } \\
\text { Lab }\end{array}$ & Target & Contractor & $\begin{array}{c}\text { WVU } \\
\text { Lab }\end{array}$ & Target & Contractor & $\begin{array}{l}\text { WVU } \\
\text { Lab }\end{array}$ & Target \\
\hline \multirow{4}{*}{ 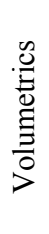 } & $\mathrm{Pb}, \%$ & - & - & 5.8 & - & - & 6.3 & - & - & 6.8 & - \\
\hline & VTM, \% & 4.0 & - & 7.7 & - & - & 5.3 & - & - & 5.5 & - \\
\hline & VFA, \% & $65-75$ & - & 60.1 & - & - & 70.8 & - & - & 72.6 & - \\
\hline & $\mathrm{D} / \mathrm{B}, \%$ & $0.6-1.2$ & - & 1.0 & - & - & 0.9 & - & - & 0.8 & - \\
\hline
\end{tabular}

\footnotetext{
${ }^{4}$ Target value is the Bailey Prediction for VMA.
} 
Table A4 Greer 19mm Contractor Blend Volumetric Results

\begin{tabular}{|c|c|c|c|c|c|c|c|c|c|c|c|}
\hline & & & \multicolumn{9}{|c|}{ Greer 19mm Contractor Blend } \\
\hline & & & \multicolumn{3}{|c|}{ Low Asphalt } & \multicolumn{3}{|c|}{ Target Asphalt } & \multicolumn{3}{|c|}{ High Asphalt } \\
\hline & & Criteria & Contractor & $\begin{array}{l}\text { WVU } \\
\text { Lab }\end{array}$ & Target & Contractor & $\begin{array}{l}\text { WVU } \\
\text { Lab }\end{array}$ & Target & Contractor & $\begin{array}{l}\text { WVU } \\
\text { Lab }\end{array}$ & Target \\
\hline \multirow{5}{*}{ 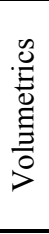 } & $\mathrm{Pb}, \%$ & - & 4.3 & 4.3 & - & 4.8 & 4.8 & - & 5.3 & 5.3 & - \\
\hline & VTM, $\%$ & 4.0 & 5.3 & 4.2 & - & 3.9 & 2.4 & - & 2.9 & 1.9 & - \\
\hline & VMA, \% & $13 \mathrm{~min}$ & 14.1 & 12.6 & - & 13.8 & 12.3 & - & 14.1 & 12.8 & - \\
\hline & VFA, $\%$ & $65-75$ & 62.1 & 66.4 & - & 71.5 & 80.3 & - & 79.7 & 85.6 & - \\
\hline & $\mathrm{D} / \mathrm{B}, \%$ & $0.6-1.2$ & 1.0 & 1.0 & - & 1.0 & 1.0 & - & 0.9 & 0.9 & - \\
\hline
\end{tabular}

Table A5 Greer 19mm Coarse Blend Volumetric Results

\begin{tabular}{|c|c|c|c|c|c|c|c|c|c|c|c|}
\hline & & \multirow[b]{3}{*}{ Criteria } & \multicolumn{9}{|c|}{ Greer 19mm Coarse Blend } \\
\hline & & & \multicolumn{3}{|c|}{ Low Asphalt } & \multicolumn{3}{|c|}{ Target Asphalt } & \multicolumn{3}{|c|}{ High Asphalt } \\
\hline & & & Contractor & $\begin{array}{l}\text { WVU } \\
\text { Lab }\end{array}$ & Target & Contractor & $\begin{array}{c}\text { WVU } \\
\text { Lab }\end{array}$ & Target & Contractor & $\begin{array}{l}\text { WVU } \\
\text { Lab }\end{array}$ & Target \\
\hline \multirow{5}{*}{ 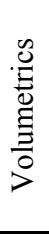 } & $\mathrm{Pb}, \%$ & - & - & 4.0 & & - & 4.5 & & - & 5.0 & \\
\hline & VTM, \% & 4.0 & - & 6.5 & & - & 4.1 & & - & 5.5 & \\
\hline & VMA, \% & $13 \mathrm{~min}$ & - & 14.2 & 13.9 & - & 13.4 & 13.6 & - & 14.9 & 14.1 \\
\hline & VFA, $\%$ & $65-75$ & - & 54.7 & & - & 69.4 & & - & 63.2 & \\
\hline & $\mathrm{D} / \mathrm{B}, \%$ & $0.6-1.2$ & - & 1.2 & & - & 1.2 & & - & 1.0 & \\
\hline
\end{tabular}

\section{Table A6 Greer 19mm Fine Blend Volumetric Results}

\begin{tabular}{|c|c|c|c|c|c|c|c|c|c|c|c|}
\hline & & \multirow[b]{3}{*}{ Criteria } & \multicolumn{9}{|c|}{ Greer 19mm Fine Blend } \\
\hline & & & \multicolumn{3}{|c|}{ Low Asphalt } & \multicolumn{3}{|c|}{ Target Asphalt } & \multicolumn{3}{|c|}{ High Asphalt } \\
\hline & & & Contractor & $\begin{array}{l}\text { WVU } \\
\text { Lab }\end{array}$ & Target & Contractor & $\begin{array}{c}\text { WVU } \\
\text { Lab }\end{array}$ & Target & Contractor & $\begin{array}{c}\text { WVU } \\
\text { Lab }\end{array}$ & Target \\
\hline \multirow{5}{*}{ 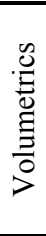 } & $\mathrm{Pb}, \%$ & - & - & 4.5 & & - & 5.0 & & - & 5.5 & \\
\hline & VTM, \% & 4.0 & - & 6.6 & & - & 5.4 & & - & 4.5 & \\
\hline & VMA, $\%$ & $13 \mathrm{~min}$ & - & 14.4 & 13.5 & - & 15.0 & 13.2 & - & 15.0 & 13.7 \\
\hline & VFA, $\%$ & $65-75$ & - & 54.4 & & - & 64.1 & & - & 70.2 & \\
\hline & $\mathrm{D} / \mathrm{B}, \%$ & $0.6-1.2$ & - & 1.2 & & - & 1.2 & & - & 1.0 & \\
\hline
\end{tabular}


Table A7 West Virginia Paving 9.5mm Contractor Blend Volumetric Results

\begin{tabular}{|c|c|c|c|c|c|c|c|c|c|c|c|}
\hline & & & \multicolumn{9}{|c|}{ West Virginia Paving 9.5mm Contractor Blend } \\
\hline & & & \multicolumn{3}{|c|}{ Low Asphalt } & \multicolumn{3}{|c|}{ Target Asphalt } & \multicolumn{3}{|c|}{ High Asphalt } \\
\hline & & Criteria & Contractor & $\begin{array}{l}\text { WVU } \\
\text { Lab }\end{array}$ & Target & Contractor & $\begin{array}{c}\text { WVU } \\
\text { Lab }\end{array}$ & Target & Contractor & $\begin{array}{c}\text { WVU } \\
\text { Lab }\end{array}$ & Target \\
\hline \multirow{5}{*}{$\begin{array}{l}\cdot \stackrel{0}{\Xi} \\
0 \\
\Xi \\
\\
0\end{array}$} & $\mathrm{~Pb}, \%$ & - & 5.4 & 5.4 & - & 5.9 & 5.9 & - & 6.4 & 6.4 & - \\
\hline & VTM, \% & 4.0 & 5.1 & 7.4 & - & 4.3 & 6.0 & - & 2.3 & 4.4 & - \\
\hline & VMA, \% & $15 \mathrm{~min}$ & 15.7 & 17.3 & - & 15.9 & 17.0 & - & 15.2 & 16.6 & - \\
\hline & VFA, $\%$ & $65-75$ & 67.0 & 57.4 & - & 73.1 & 64.6 & - & 85.1 & 73.3 & - \\
\hline & $\mathrm{D} / \mathrm{B}, \%$ & 0.6-1.2 & 1.0 & 1.0 & - & 0.9 & 0.9 & - & 0.8 & 0.8 & - \\
\hline
\end{tabular}

Table A8 West Virginia Paving 9.5mm Coarse Blend Volumetric Results

\begin{tabular}{|c|c|c|c|c|c|c|c|c|c|c|c|}
\hline & & & \multicolumn{9}{|c|}{ West Virginia Paving 9.5mm Coarse Blend } \\
\hline & & & \multicolumn{3}{|c|}{ Low Asphalt } & \multicolumn{3}{|c|}{ Target Asphalt } & \multicolumn{3}{|c|}{ High Asphalt } \\
\hline & & Criteria & Contractor & $\begin{array}{c}\text { WVU } \\
\text { Lab }\end{array}$ & Target & Contractor & $\begin{array}{c}\text { WVU } \\
\text { Lab }\end{array}$ & Target & Contractor & $\begin{array}{c}\text { WVU } \\
\text { Lab }\end{array}$ & Target \\
\hline \multirow{5}{*}{$\begin{array}{l}\frac{\tilde{U}}{\Xi} \\
\frac{0}{0} \\
\frac{\Xi}{0} \\
>\end{array}$} & $\mathrm{Pb}, \%$ & - & - & 4.5 & & - & 5.0 & & - & 5.5 & \\
\hline & VTM, \% & 4.0 & - & 9.9 & & - & 9.2 & & - & 8.0 & \\
\hline & VMA, $\%$ & $15 \mathrm{~min}$ & - & 17.6 & 19.5 & - & 18.1 & 19.2 & - & 17.8 & 18.8 \\
\hline & VFA, $\%$ & $65-75$ & - & 44.0 & & - & 49.4 & & - & 54.9 & \\
\hline & $\mathrm{D} / \mathrm{B}, \%$ & $0.6-1.2$ & - & 1.0 & & - & 0.9 & & - & 0.8 & \\
\hline
\end{tabular}

Table A9 West Virginia Paving 9.5mm Fine Blend Volumetric Results

\begin{tabular}{|c|c|c|c|c|c|c|c|c|c|c|c|}
\hline & & \multirow[b]{3}{*}{ Criteria } & \multicolumn{9}{|c|}{ West Virginia Paving 9.5mm Fine Blend } \\
\hline & & & \multicolumn{3}{|c|}{ Low Asphalt } & \multicolumn{3}{|c|}{ Target Asphalt } & \multicolumn{3}{|c|}{ High Asphalt } \\
\hline & & & Contractor & $\begin{array}{c}\text { WVU } \\
\text { Lab }\end{array}$ & Target & Contractor & $\begin{array}{c}\text { WVU } \\
\text { Lab }\end{array}$ & Target & Contractor & $\begin{array}{c}\text { WVU } \\
\text { Lab }\end{array}$ & Target \\
\hline \multirow{5}{*}{ 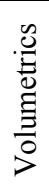 } & $\mathrm{Pb}, \%$ & - & - & 5.8 & & - & 6.3 & & - & 6.8 & \\
\hline & VTM, $\%$ & 4.0 & - & 7.3 & & - & 6.4 & & - & 5.0 & \\
\hline & VMA, \% & $15 \mathrm{~min}$ & - & 18.1 & 18.1 & - & 18.1 & 17.8 & - & 17.9 & 17.4 \\
\hline & VFA, $\%$ & $65-75$ & - & 59.6 & & - & 64.5 & & - & 72.2 & \\
\hline & $\mathrm{D} / \mathrm{B}, \%$ & $0.6-1.2$ & - & 1.0 & & - & 0.9 & & - & 0.8 & \\
\hline
\end{tabular}


Table A10 West Virginia Paving Wearing I Contractor Blend Volumetric Results

\begin{tabular}{|c|c|c|c|c|c|c|c|c|c|c|c|}
\hline & & \multirow[b]{3}{*}{ Criteria } & \multicolumn{9}{|c|}{ West Virginia Paving Wearing I Contractor Blend } \\
\hline & & & \multicolumn{3}{|c|}{ Low Asphalt } & \multicolumn{3}{|c|}{ Target Asphalt } & \multicolumn{3}{|c|}{ High Asphalt } \\
\hline & & & Contractor & $\begin{array}{l}\text { WVU } \\
\text { Lab }\end{array}$ & Target & Contractor & $\begin{array}{l}\text { WVU } \\
\text { Lab }\end{array}$ & Target & Contractor & $\begin{array}{c}\text { WVU } \\
\text { Lab }\end{array}$ & Target \\
\hline \multirow{7}{*}{ 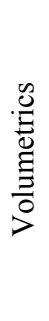 } & $\mathrm{Pb}, \%$ & - & 5.2 & 5.2 & - & 5.7 & 5.7 & - & 6.2 & 6.2 & - \\
\hline & VTM, \% & 4.0 & 5.7 & 8.5 & - & 4.0 & 8.0 & - & 2.4 & 6.9 & - \\
\hline & VMA, \% & $15 \mathrm{~min}$ & 15.9 & 16.4 & - & 15.3 & 17.1 & - & 15.0 & 16.9 & - \\
\hline & VFA, \% & $65-75$ & 64.0 & 48.1 & - & 74.0 & 53.3 & - & 83.9 & 59.1 & - \\
\hline & $\mathrm{D} / \mathrm{B}, \%$ & $0.6-1.2$ & 1.0 & 1.0 & - & 1.0 & 1.0 & - & 0.9 & 0.8 & - \\
\hline & Stability & $8000 \mathrm{~N}$ & - & 7828 & & - & 12452 & & - & 6048 & \\
\hline & Flow & $8-14$ & - & 7.1 & & - & 6.6 & & - & 13.7 & \\
\hline
\end{tabular}

Table A11 West Virginia Paving Wearing I Coarse Blend Volumetric Results

\begin{tabular}{|c|c|c|c|c|c|c|c|c|c|c|c|}
\hline & & & \multicolumn{9}{|c|}{ West Virginia Paving Wearing I Coarse Blend } \\
\hline & & & \multicolumn{3}{|c|}{ Low Asphalt } & \multicolumn{3}{|c|}{ Target Asphalt } & \multicolumn{3}{|c|}{ High Asphalt } \\
\hline & & Criteria & Contractor & $\begin{array}{c}\text { WVU } \\
\text { Lab }\end{array}$ & Target & Contractor & $\begin{array}{l}\text { WVU } \\
\text { Lab }\end{array}$ & Target & Contractor & $\begin{array}{c}\text { WVU } \\
\text { Lab }\end{array}$ & Target \\
\hline \multirow{7}{*}{ 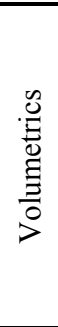 } & $\mathrm{Pb}, \%$ & - & - & 4.5 & & - & 5.0 & & - & 5.5 & \\
\hline & VTM, \% & 4.0 & - & 10.6 & & - & 8.5 & & - & 8.2 & \\
\hline & VMA, $\%$ & $15 \mathrm{~min}$ & - & 17.7 & 17.0 & - & 16.6 & 17.7 & - & 17.2 & 17.5 \\
\hline & VFA, $\%$ & $65-75$ & - & 40.1 & & - & 48.7 & & - & 52.6 & \\
\hline & $\mathrm{D} / \mathrm{B}, \%$ & $0.6-1.2$ & - & 1.0 & & - & 1.0 & & - & 0.8 & \\
\hline & Stability & $8000 \mathrm{~N}$ & - & 7560 & & - & 9608 & & - & 9252 & \\
\hline & Flow & $8-14$ & - & 7.1 & & - & 6.6 & & - & 8.1 & \\
\hline
\end{tabular}

Table A12 West Virginia Paving Wearing I Fine Blend Volumetric Results

\begin{tabular}{|c|c|c|c|c|c|c|c|c|c|c|c|}
\hline & & & \multicolumn{9}{|c|}{ West Virginia Paving Wearing I Fine Blend } \\
\hline & & & \multicolumn{3}{|c|}{ Low Asphalt } & \multicolumn{3}{|c|}{ Target Asphalt } & \multicolumn{3}{|c|}{ High Asphalt } \\
\hline & & Criteria & Contractor & $\begin{array}{l}\text { WVU } \\
\text { Lab }\end{array}$ & Target & Contractor & $\begin{array}{c}\text { WVU } \\
\text { Lab }\end{array}$ & Target & Contractor & $\begin{array}{l}\text { WVU } \\
\text { Lab }\end{array}$ & Target \\
\hline \multirow{7}{*}{ 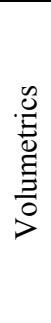 } & $\mathrm{Pb}, \%$ & - & - & 6.4 & & - & 6.9 & & - & 7.4 & \\
\hline & VTM, \% & 4.0 & - & 5.1 & & - & 4.8 & & - & 2.7 & \\
\hline & VMA, $\%$ & $15 \mathrm{~min}$ & - & 15.2 & 19.0 & - & 15.9 & 19.7 & - & 14.9 & 19.5 \\
\hline & VFA, \% & $65-75$ & - & 66.7 & & - & 70.1 & & - & 81.8 & \\
\hline & $\mathrm{D} / \mathrm{B}, \%$ & $0.6-1.2$ & - & 1.0 & & - & 1.0 & & - & 0.8 & \\
\hline & Stability & $8000 \mathrm{~N}$ & - & 8184 & & - & 10852 & & - & 10228 & \\
\hline & Flow & $8-14$ & - & 14.2 & & - & 14.2 & & - & 15.2 & \\
\hline
\end{tabular}




\section{APPENDIX B - ANOVA}

Table B1 Regression Analysis of VMA for Bailey Prediction versus WVU Lab Results for All Blends

\begin{tabular}{|c|c|c|c|c|c|}
\hline \multicolumn{2}{|c|}{ Regression Statistics } & & & & \\
\hline Multiple R & 0.58 & & & & \\
\hline R Square & 0.34 & & & & \\
\hline Adjusted R Square & 0.31 & & & & \\
\hline Standard Error & 1.83 & & & & \\
\hline Observations & 24 & & & & \\
\hline \multicolumn{2}{|c|}{ ANOVA } & & & & \\
\hline & $d f$ & SS & MS & $F$ & Significance F \\
\hline Regression & 1 & 37.3 & 37.26 & 11.11 & $3.01 \mathrm{E}-03$ \\
\hline Residual & 22 & 73.8 & 3.35 & & \\
\hline \multirow[t]{2}{*}{ Total } & 23 & 111.0 & & & \\
\hline & Coefficients & Standard Error & $t$ Stat & & \\
\hline Intercept & 5.27 & 3.56 & 1.48 & & \\
\hline X Variable 1 & 0.70 & 0.21 & -1.41 & & \\
\hline
\end{tabular}

Table B2 Regression Analysis of VMA for Bailey Prediction versus WVU Lab Results for SuperPave Blends

\begin{tabular}{|c|c|c|c|c|c|}
\hline \multicolumn{2}{|c|}{ Regression Statistics } & & & & \\
\hline Multiple R & 0.83 & & & & \\
\hline R Square & 0.69 & & & & \\
\hline Adjusted R Square & 0.68 & & & & \\
\hline Standard Error & 1.32 & & & & \\
\hline Observations & 18 & & & & \\
\hline \multicolumn{6}{|c|}{ ANOVA } \\
\hline & $d f$ & SS & MS & $F$ & Significance $F$ \\
\hline Regression & 1 & 62.9 & 62.94 & 36.38 & $1.74 \mathrm{E}-05$ \\
\hline Residual & 16 & 27.7 & 1.73 & & \\
\hline \multirow[t]{2}{*}{ Total } & 17 & 90.6 & & & \\
\hline & Coefficients & Standard Error & t Stat & & \\
\hline Intercept & 0.12 & 2.76 & 0.04 & & \\
\hline $\mathrm{X}$ Variable 1 & 0.97 & 0.16 & 0.18 & & \\
\hline
\end{tabular}

